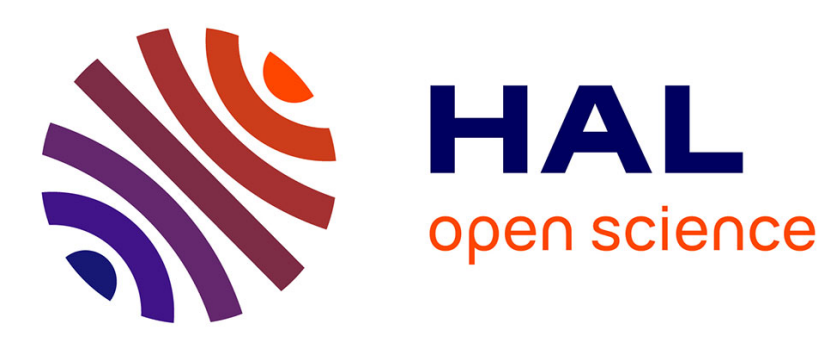

\title{
Les ateliers de céramique byzantine de Nicée/Iznik et leur production (Xe-début XIVe siècle)
}

Véronique François

\section{To cite this version:}

Véronique François. Les ateliers de céramique byzantine de Nicée/Iznik et leur production (Xe-début XIVe siècle). Bulletin de Correspondance Hellenique, 1997, 121.1, pp.423-458. 10.3406/bch.1997.1637 . halshs-00752108

\section{HAL Id: halshs-00752108 \\ https://shs.hal.science/halshs-00752108}

Submitted on 23 May 2017

HAL is a multi-disciplinary open access archive for the deposit and dissemination of scientific research documents, whether they are published or not. The documents may come from teaching and research institutions in France or abroad, or from public or private research centers.
L'archive ouverte pluridisciplinaire HAL, est destinée au dépôt et à la diffusion de documents scientifiques de niveau recherche, publiés ou non, émanant des établissements d'enseignement et de recherche français ou étrangers, des laboratoires publics ou privés. 
Les ateliers de céramique byzantine de Nicée/lznik et leur production (Xe-début XIVe siècle)

\section{Véronique François}

\section{Citer ce document / Cite this document :}

François Véronique. Les ateliers de céramique byzantine de Nicée/lznik et leur production (Xe-début XIVe siècle). In: Bulletin de correspondance hellénique. Volume 121, livraison 1, 1997. pp. 411-442;

doi : 10.3406/bch.1997.1637

http://www.persee.fr/doc/bch_0007-4217_1997_num_121_1_1637

Document généré le 19/05/2016 


\title{
пврі́іпџџ
}

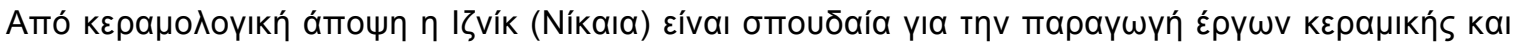

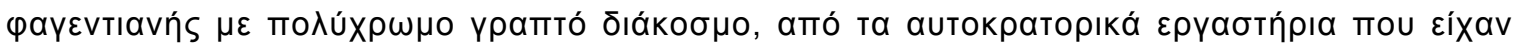

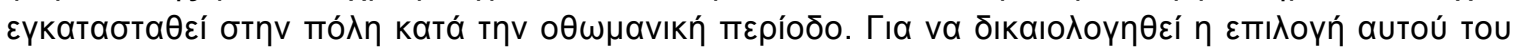

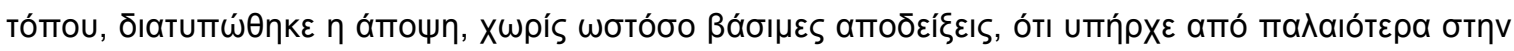

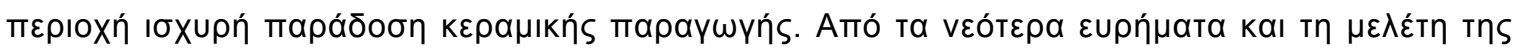

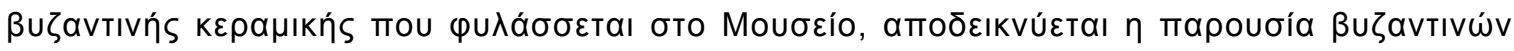

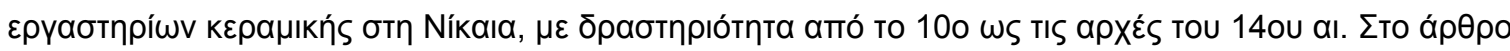

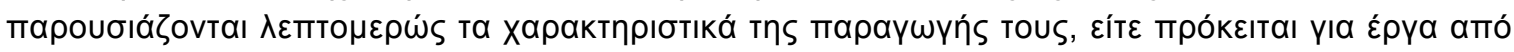

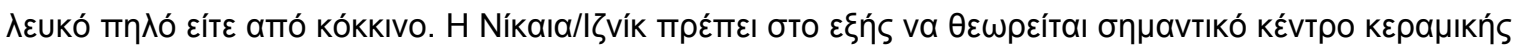

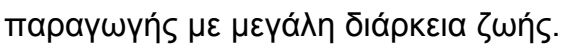

\section{Résumé}

D'un point de vue céramologique, Iznik est célèbre pour ses productions de céramique et faïence peinte polychrome issues des ateliers impériaux installés, à l'époque ottomane, dans la ville. Pour justifier le choix de ce lieu, on a avancé, sans pour autant en avoir de preuve matérielle, qu'il existait antérieurement une tradition potière bien établie dans la région. Les découvertes de terrain ainsi que l'étude de la céramique byzantine conservée au musée m'ont permis de démontrer l'existence d'ateliers de potiers byzantins en activité entre le Xe et le début du XIVe s., à Nicée. Les caractéristiques de leurs productions, qu'elles soient à pâte blanche ou à pâte rouge, sont présentées en détail dans cet article. Nicée/lznik doit désormais être considéré comme un grand centre de production de céramique en activité sur une très longue durée.

\begin{abstract}
From the point of view of ceramics, Iznik is famous for its output of pottery and painted polychrome faïence produced in the imperial workshops established in the town during the Ottoman period. To explain this choice of location, it has been suggested, without any concrete proof, that a wellestablished potting tradition had previously existed in the region. Discoveries on the spot together with a study of the Byzantine pottery preserved in the museum enabled me to demonstrate the existence of Byzantine potters who were active in Nicaea between the 10th and the beginning of the 14th century. The characteristics of their wares, whether of white or red day, are presented in detail in this article. Nicaea/lznik must henceforth be regarded as a considerable centre of ceramic production, which was in operation over a long period of time.
\end{abstract}




\section{Les ateliers de céramique byzantine de Nicée/Iznik et leur production (Xe-début XIV siècle)*}

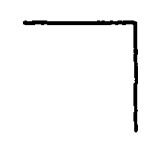

D'un point de vue céramologique, Iznik est célèbre pour ses productions de céramique et faïence peinte polychrome issues des ateliers impériaux installés, à l'époque ottomane, dans la ville. On s'est interrogé, sans pour autant trouver de réponse satisfaisante, sur le choix de cette localité comme centre de fabrication officiel de la vaisselle de luxe de l'Empire'.

Peu de temps après l'arrivée d'Orhan en 1331, Iznik, devenue résidence du sultan, est décrite par Ibn Battûta, comme peu peuplée et en ruine ${ }^{2}$. Situation confirmée en 1354 par Grégoire Palamas qui, prisonnier des Turcs, constate son état de délabrement ${ }^{3}$. Au milieu du XVI ${ }^{e}$ s., âge d'or des productions de faïence, l'état de la cité est resté le même, un Européen de passage en 1568 va jusqu'à parler de ville désertée Tous les récits des voyageurs, jusqu'au $\mathrm{XIX}^{e}{ }^{\mathrm{s}} .^{5}$, s'accordent à décrire une ville en ruine comptant une population fort réduite ${ }^{6}$. Par ailleurs, sans être trop éloignée d'Istanbul, son accès n'est guère aisép : il faut, par exemple, compter deux jours de route pour traverser les montagnes jusqu’à Karamürsel puis huit heures de bateau pour gagner la

* J'aimerais remercier M. Tayan Sevil, Directeur du Musée archéologique d'Iznik, pour sa gentillesse et pour la bonne volonté dont il a fait preuve afin de faciliter mes recherches. Je suis reconnaissante à Bedri Yalman, Directeur des fouilles du Theátre, pour les informations qu'il a bien voulu me livrer et pour le matériel qu'il m'a montré. Enfin, j'aimerais associer à ce travail mon ami Mahmoud Effendi.

\section{Abréviations utilisées :}

N. ATASOY, J. RABY, Iznik = N. ATASOY, J. RABY, Iznik. La poterie en Turquie ottomane (1990).

MEGAW, Zeuxippus Ware = A. H. S. MEGAW, * Zeuxippus Ware ", BSA 63 (1968), p. 67-88.

RABY, Description $=$ J. RABY, $\propto$ A Seventeenth Century Description of Iznik-Nicaea n, MDAI(I) 26 (1976), p. 149-188.

1 N. ATASOY, J. RABY, Iznik, p. 21.

2 C. DEFREMERY, B. SANGUINETTI (éds), Voyages d'Ibn Battûta II (Paris, 1854), p. 323.
3 P. ANARKIS, - The Captivity of Gregory Palamas among the Turks ", Speculum 26 (1951), p. 104-108.

$4 \mathrm{~L}$. RAUTER, in R. RöHRICHT, H. MEISSNER (éds), Deutsche Pilgerreisen nach dem heiligen Lande I (1880), p. 430.

5 Pour de nombreuses références sur les voyageurs, voir RABY, Description, p. 149-188.

6 On estime entre 20000 et 30000 la population à l'époque byzantine, P. CHARANIS, * A Note on the Population and Cities of the Byzantine Empire in the Thirteenth Century ", The Joshua 'Starr Memorial Volume, Jewish Social Studies 5 (1953), p. 144145. À l'époque ottomane, grâce aux indications fournies par des registres cadastraux, on évalue au dixième le nombre d'habitants ; cf. J. RABY, loc. cit. (supra, n. 5), p. 170-171. 7 Sur les obstacles naturels et les divers itinéraires terrestres et maritimes entre Constantinople et Nicée, voir J. LEFORT, - Les communications entre Constantinople et la Bithynie ${ }_{\text {, in }}$ C. MANGO, G. DAGRON (éds), Constantinople and its Hinterland (1995), p. 207-218. 
capitale $^{8}$. Quels que soient les itinéraires, maritimes ou terrestres, tous ont leurs inconvénients tels que les obstacles naturels, les incertitudes de la navigation ou les ruptures de charges qui ne favorisent pas le transport de vaisselle, marchandise fragile s'il en est. Certes, la région est riche en combustible et la présence du lac assure une grande facilité d'approvisionnement en eau, le bois et l'eau étant consommés en grande quantité dans la fabrication de la poterie. Mais on ne peut voir là une raison suffisante pour y établir les ateliers impériaux, ces conditions pouvant être réunies dans les environs même d'Istanbul. On a alors envisagé, comme cause essentielle de cette installation, l'existence d'une tradition potière bien établie dans la région, sans pour autant en avoir de preuve matérielle?. Pourtant, certains indices indiquent l'existence d'une fabrication régionale. Quelques textes mentionnent des productions de céramique en Bithynie: Nicolas Mésaritès, dans son récit de voyage à Nicée en 1208, signale une grande activité dans le commerce des poteries, bien qu'il ne fasse référence qu’à des cargaisons de jarres à vin ${ }^{10}$; plus tard, au XV $\mathrm{XV}^{\mathrm{e}}$ s., le chroniqueur Asıkpaşazâde rapporte que les potiers chrétiens de Bilecik, à $35 \mathrm{~km}$ au Sud-Ouest d'Iznik, sont célèbres pour leurs poteries qu'ils vendent à la foire hebdomadaire d'Eskişehir " ${ }^{11}$ Par ailleurs, la présence, au Sud de Bilecik, de plusieurs lieux désignés comme "kiremit ocaklı " ou fours de tuile, suppose l'existence d'ateliers de tuiliers donc de gisements d'argile ${ }^{12}$. Enfin, le dernier élément qui peut témoigner en faveur d'une activité potière locale, c'est la décoration de tuiles à glaçure verte sur l'imaret édifié à Iznik sur l'ordre d'Orhan ${ }^{13}$ en 1334-1335. Ces tuiles à pâte argileuse, glaçure plombifere, marquées par des traces d'arrachements de pernette qui indiquent une cuisson à l'horizontale, n'appartiennent pas techniquement aux traditions seldjoukides et ottomanes ${ }^{14}$. La date de construction de l'imaret et la rapidité avec laquelle il a été érigé supposent l'utilisation des ressources artisanales locales, en l'occurrence les productions de potiers déjà installés à Iznik ou à proximité de la ville.

En complément de ces multiples indices, je me propose de présenter dans cet article des découvertes matérielles qui témoignent de l'existence, à Nicée, d'ateliers de potiers byzantins en activité entre le $\mathrm{X}^{\mathrm{e}}$ et le début du XIV $\mathrm{X}^{\mathrm{e}} \mathrm{s}$.

Les fragments de céramique byzantine étudiés ici constituent un échantillonnage représentatif des découvertes de Bithynie et proviennent de contextes généraux de découverte très différents. Mon premier contact avec la céramique byzantine dans la région s'est fait à travers les tessons recueillis au cours de plusieurs campagnes d'une

8 N. ATASOY, J. RABY, Iznik, p. 22.

9 lbid.

10 A. HEISENBERG, Neue Quellen zur Geschichte des lateinischen Kaisertums und der Kirchenunion, II. Die Unionsverhandlungen vom 30. August 1206, Patriarchenwahl und Kaiserkrönung in Nikaia 1208, SBAW (1923/2), p. 9-11 et p. 44, I. 31-35.
11 ASIKPASAZĀDE, Tevàrih-i Al-i 'Osman: 'Asıkpasazade Taribi (éd. 'ALI BEY) (Istanbul, 1914 ; réimpr. Londres, 1970), p. 12. 12 Je remercie Irène Beldiceanu qui a attiré mon attention sur ces toponymes bithyniens relevés dans: Carte de Turquie, 1: 200000 (Ankara, 1951).

13 N. ATASOY, J. RABY, Iznik, p. 22.

14 Les pâtes sont des frittes et les carreaux sont cuits en position verticale. 
prospection extensive destinée à établir l'histoire de l'occupation du sol de la Bithynie au Moyen Âge ${ }^{15}$. Sur les sites byzantins visités dans une vaste région, sites vers lesquels notre équipe a été conduite par des textes, des toponymes, les indications des habitants ou des vestiges très visibles, les tessons - souvent très fragmentaires et mal conservés - témoignaient d'une homogénéité de style qui déjà militait en faveur d'une unité de la production ${ }^{16}$. Le matériel du musée archéologique, sur lequel j'ai ensuite travaillé, a été retrouvé à l'occasion de divers travaux de creusement effectués dans la ville, notamment dans une tranchée ouverte à l'arrière des bâtiments de la Poste, Kiliç Arslan Caddesi, en 1987 ${ }^{17}$. Par ailleurs, l'observation de la collection de vases byzantins présentée dans les vitrines du Musée m'a permis de restituer les formes complètes et de mieux appréhender l'organisation du décor ${ }^{18}$. Ces vases proviennent, pour la plupart, des fouilles menées dans le centre d'Iznik, c'est-à-dire les fouilles des ateliers ottomans ${ }^{19}$ et du Théâtre romain ${ }^{20}$. Dans les deux cas, aucune indication chronologique n'est fournie par les fouilles. La céramique byzantine, très abondante au Théâtre, provient de remblais prélevés ailleurs dans la ville et se trouve mélangée à des tessons hellénistiques, romains et ottomans. Enfin, j'ai eu un accès rapide à une partie de ce matériel conservée dans les dépôts ${ }^{21}$.

\section{Les pâtes blanches}

L'étude de la céramique à pâte blanche, part importante des productions byzantines, a été récemment revue et précisée par J. W. Hayes, à partir des découvertes abondantes faites dans les fouilles de Saraçhane à Istanbul2 ${ }^{22}$. C'est cette typologie nouvelle qui a été adoptée pour caractériser les tessons à pâte blanche d'Iznik — Glazed White Ware II, Glazed White Ware IV et Polychrome Ware - qui s'échelonnent du X au début du XIII' s. (fig. 1-2).

Divers types de Glaze White Ware II, céramique à pâte blanche par excellence d'époques macédonienne et comnène, sont représentés. On trouve des exemplaires de

15 Campagnes de 1990, 1991, 1993, 1994 dirigées par J. Lefort et B. Geyer.

$16 \mathrm{~V}$. FRANÇOIS, "La céramique byzantine en Bithynie ", in J. LEFORT et al., La Bithynie au Moyen Âge (sous presse). 17 Outre la céramique byzantine, on y a retrouvé de la céramique ottomane et des pernettes, voir V. FRANçOIS, "Céramique ottomane de tradition byzantine d'Iznik ", AnAnt 4 (1996), p. 231-245.

18 Pour des raisons administratives, il ne nous a pas été permis de sortir ces vases des vitrines. Nous ne pourrons donc en présenter aucun dessin. Quant aux photographies, prises à travers les vitrines, elles sont difficilement utilisables. 19 0. ASLANAPA, S. YETKIN, A. ALTUN, The iznik Tile Kiln Excavations (The Second Round: 1981-1988) (1989).
20 B. YALMAN, * Iznik Theatre, 1982 ", AS 33 (1983), p. 250 252 ; id., * Iznik Theatre, 1983 *, AS 34 (1984), p. 222-223; Id., - Iznik Tiyatro KazıSI, 1991 ", XIV. Kazı Sonuçları Toplantısı, Ankara 25-29 mayıs 1992 II (1993), p. 181-203.

21 Signalons que la quantité de fragments - notamment des pâtes blanches - retrouvés dans les fouilles du Thêâtre est impressionnante. On regrette qu'aucune étude concernant la céramique du Theâtre n'ait, jusqu'à présent, été entreprise. Ces vases observés mais non étudiés n'apparaîtront pas dans le catalogue où seuls les fragments trouvés en prospection et ceux enregistrés au musée seront présentés en détails. $22 \mathrm{~J}$. W. HAYES, Excavations at Saraçhane in Istanbul, 2. The Pottery (1992), p. 12-38. 
414 VÉRONIQUE FRANÇOIS - LES ATELIERS DE CÉRAMIQUE BYZANTINE DE NICÉE/IZNIK ET LEUR PRODUCTION (Xe.DÉBUT XIVe S.)

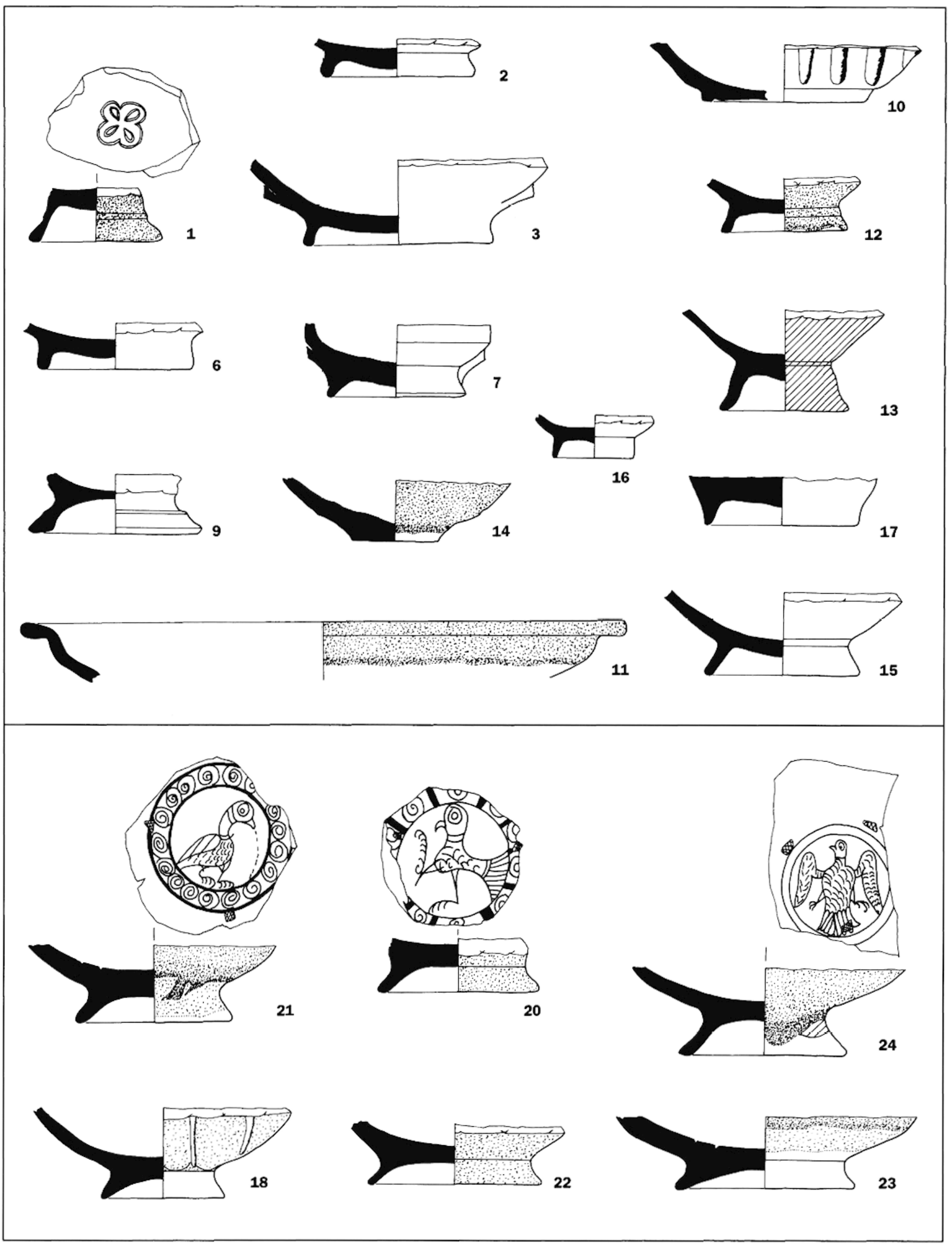

Fig. 1. Céramique à păte blanche $\left(n^{\circ s} 1-3,6-7,9-17\right)$ et céramique incisée $\left(n^{\circ s} 18,20-24\right)(1: 3)$. 

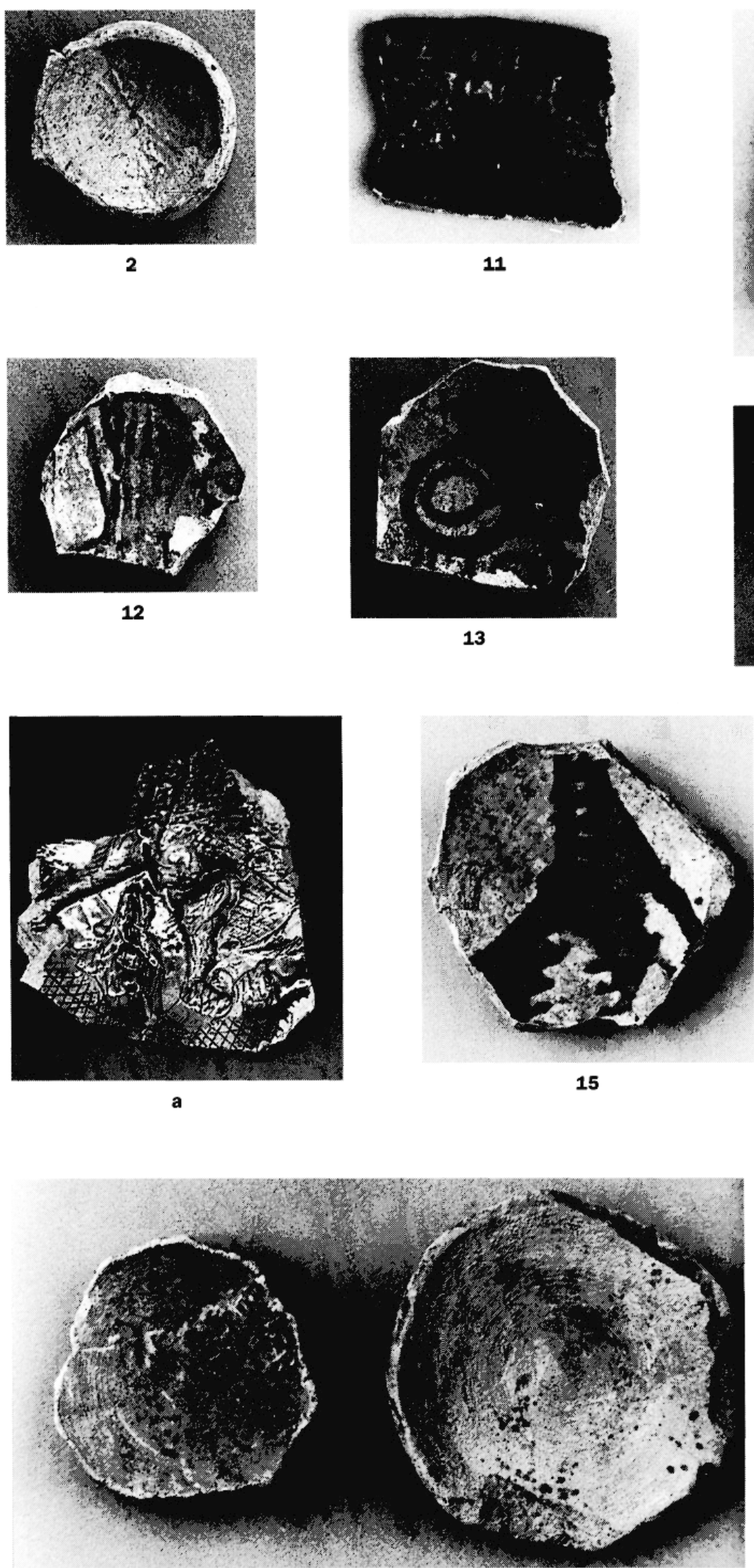

16
2

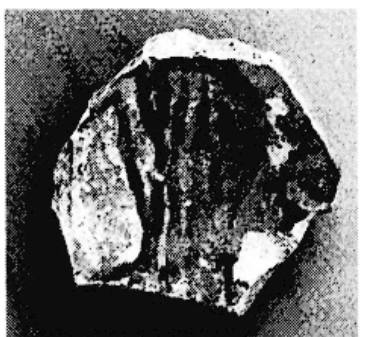

12

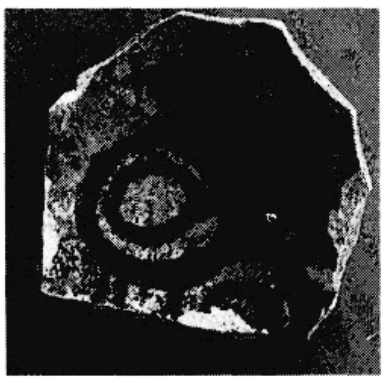

13

15

a

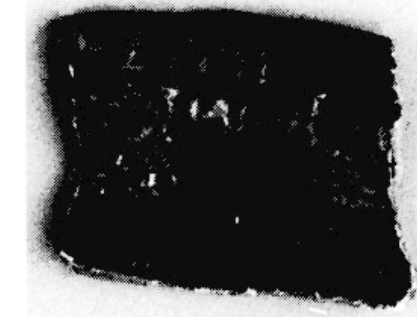

11

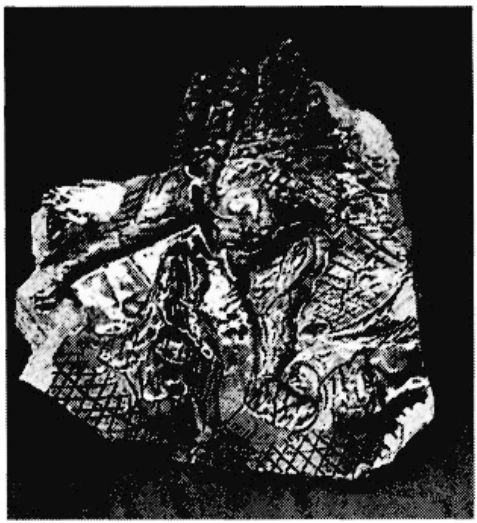

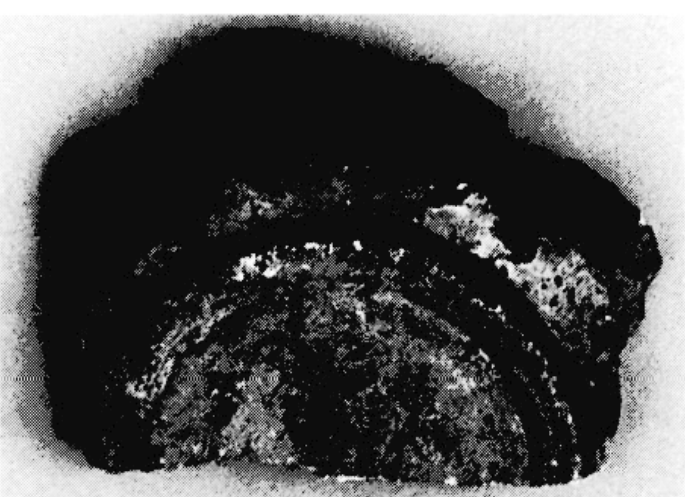

10
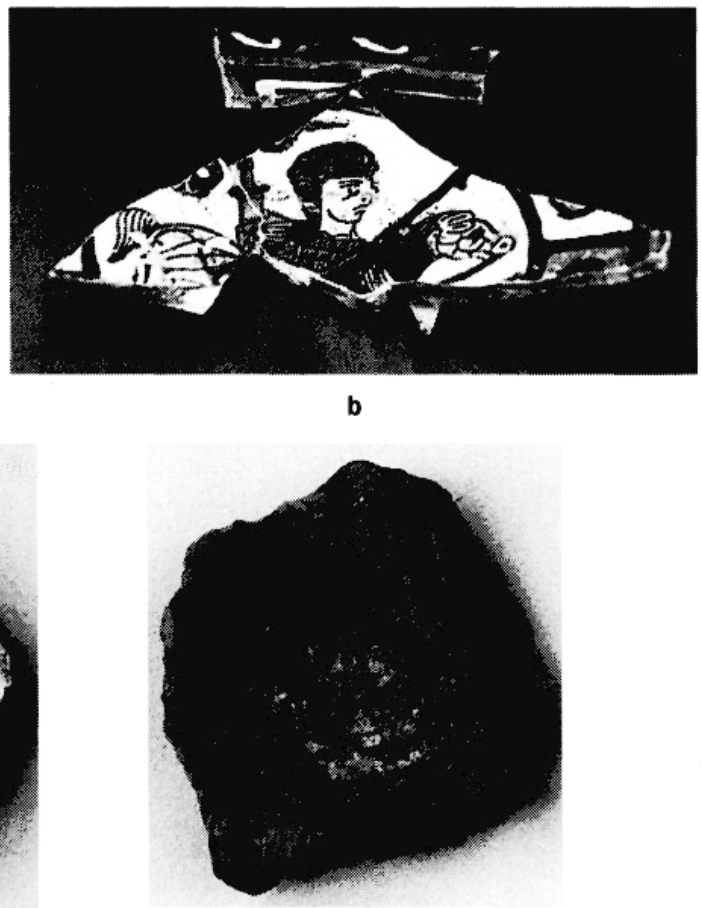

63

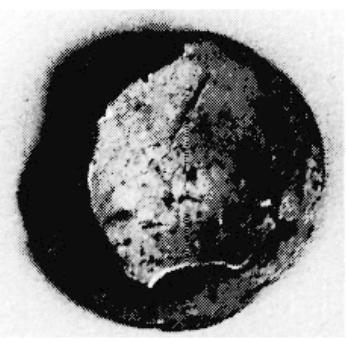

65

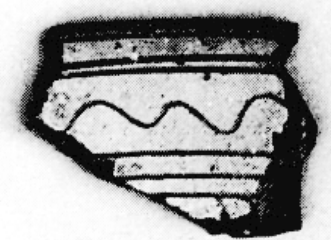

66

Flg. 2. Céramique à pâte blanche $\left(n^{\circ 5} 2,10-13,15-17, a, b\right)$ et vases à pâte rouge rejetés en cours d'élaboration $\left(n^{\circ 5} 63,65-66\right)$. 
Glaze White Ware II de type 3 à pâte blanche, fine et bien cuite ${ }^{23}$; les glaçures plombiferes, appliquées directement sur la pâte, sont jaune pâle, vert clair et vert bouteille, parfois mouchetées. La plupart de ces vases sont décorés de motifs estampés simples - trèfle à quatre feuilles, rosette et palmette insérés dans des médaillons centraux délimités par des cercles concentriques ou par des bandeaux compartimentés ( $\mathrm{n}^{\text {os }} 1$ $5)^{24}$. D'autres vases ont une glaçure monochrome ou polychrome sans décor $\left(n^{\circ s} 6,8\right.$ 9). Les fragments observés appartiennent à des vases de petites dimensions de forme ouverte, munis de pieds annulaires bas. À Saraçhane, cette céramique, présente dans des contextes du $\mathrm{X}^{\mathrm{e}}$ s., surpasse au XI $\mathrm{XI}^{\mathrm{e}}$ les autres types de pâte blanche. Un exemplaire du type 2 , daté de la première moitié du $\mathrm{XI}^{\mathrm{e}}$ s., retrouvé dans le matériel du Théâtre, est orné d'un griffon estampé sous glaçure vert bouteille ${ }^{25}$. La Glaze White Ware II de type 5 est illustrée par le fond et le bas de la panse d'un grand vase exposé au Musée, orné d'un félin en relief avec, placé entre ses pattes, un petit animal, le tout entouré d'un bandeau de hachures incisées; la glaçure est jaune-brunâtre (fig. 2a). Cet exemplaire est très proche d'un fragment de Saraçhane qui peut remonter au début du $\mathrm{XI}^{\mathrm{e}} s^{26}$. De petites coupes à deux anses de type $14\left(\mathrm{n}^{\circ} 7\right)$, très fréquentes au Théâtre, sont datées du $\mathrm{XI}^{\mathrm{e}} \mathrm{s.}^{27}$. Un fond plat à panse godronnée et un bord à marli ornés de deux rangées d'incisions parallèles couverts d'une glaçure brillante en dégradé de jaune, brun et vert clair $\left(\mathrm{n}^{\text {os }} 10,11\right)$, peuvent être considérés comme des variantes de la Glaze White Ware II attribuées au XI ${ }^{\mathrm{e}} .^{28}$. Enfin, on trouve quelques fonds peints aux parois minces de type Glaze White Ware $I V$, datés de la fin XII -début XIII ${ }^{e}$ s. ( $\mathrm{n}^{\text {os }}$ 12-15). Ils sont ornés de motifs peints grossièrement en vert et noir, les pigments ayant parfois tendance à fuser. La glaçure jaune pâle ou incolore, appliquée en fine couche, est généralement mal conservée ${ }^{29}$.

Il existe aussi à Iznik, une autre catégorie de pâte blanche, la Polychrome Ware, une des plus fameuses céramiques byzantines bien qu'elle ne représente, en fait, qu'une toute petite partie des productions. Au Musée, elle est illustrée par un plat de grandes dimensions orné, dans un médaillon central dont le bandeau est compartimenté, d'un cavalier armé peint polychrome en brun, rose et vert ; la glaçure est incolore (fig. 2b). Sur un fragment peint en vert, noir et rouge, retrouvé dans les fouilles des fours ottomans, on voit un homme de face vêtu d'une cotte courte, les cheveux coupés au carré, qui semble courir ; à sa droite une inscription partiellement conservée est tracée en lettres grecques: OMHC. Parmi les fragments du Théâtre, on compte un bord décoré d'un bandeau de petits arcs alternés avec un trait vertical peints en jaune et vert et délimités par un trait noir, et un fragment de forme fermée à paroi fine dont la panse est décorée de fleurettes peintes en noir avec rehauts vert-bleuâtre, insérées dans de petits médaillons, se détachant sur un semis de points rouges; la glaçure

23 lbid., p. 22-23, fig. 7.10-16, pl. 5h-i.

24 Les chiffres en gras renvoient au $n^{\circ}$ du tesson dans le catalogue, qui lui-méme renvoie aux illustrations. 25 ibid., p. 22, pl. 5c.
26 lbid., p. 23, pl. 5k.

27 Ibid., p. 25-27, fig. 9.

28 Ibid., p. 26 , fig. 9.25 et p. 216.

29 ibid., p. 30-31, pl. 7a-c. 
brillante est incolore ${ }^{30}$. Ces vases semblent appartenir aux classes 1 et 2 définies par J. W. Hayes et dateraient de la fin du Xe- $\mathrm{XI}^{\mathrm{e}} \mathrm{s}^{31}$.

Ce matériel d'Iznik nous permet-il d'élucider en partie la question du lieu de production de cette céramique à pâte blanche si abondante à Istanbul ${ }^{32}$ ? Bien que l'existence d'ateliers constantinopolitains reste, en l'absence de toutes traces matérielles, hypothétique, la quantité considérable de pâte blanche retrouvée à Istanbul conduit à envisager une source d'approvisionnement proche de la capitale. Dans ce sens, on attribue régulièrement à Nicomédie/Izmit une production de pâte blanche, suggérée par la référence à un texte ${ }^{33}$ daté de la fin du XII ${ }^{e} .{ }^{34}$ qui mentionne une

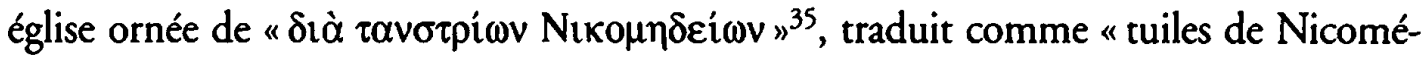
die " ${ }^{36}$. Par ailleurs, plusieurs plaques peintes polychromes à pâte blanche apparaissent dans les inventaires des musées comme originaires de cette même ville bithynienne ${ }^{37}$. Cette référence à Nicomédie n'implique pas que ces objets aient été fabriqués sur place, on peut par exemple imaginer que Nicomédie est seulement un centre de distribution. Cette hypothèse est d'autant plus vraisemblable que jusqu’à présent aucune découverte matérielle ne confirme l'existence d'une production nicomédienne. En revanche, Nicée peut être considérée comme une des sources de l'approvisionnement de Constantinople. En effet, un indicateur décisif montre que Nicée était alors un centre de production. Non seulement les fouilles du Théâtre ont livré un très important volume de tessons à pâte blanche, mais on a aussi trouvé parmi ces fragments de nombreux vases, ratés de cuisson, rejetés avant l'application de la glaçure. Deux fonds de cette nature $\left(\mathrm{n}^{\mathrm{os}} 16,17\right)$, découverts parmi le matériel de la Poste, confirment à leur tour l'existence d'une fabrication locale.

Ainsi, la quantité impressionnante de céramique retrouvée, la diversité des types représentés, couvrant une période allant du $\mathrm{X}^{\mathrm{e}}$ au début du XIII ${ }^{\mathrm{e}}$ s., la découverte

30 Pour des exemples proches, voir ibid., pl. 8 k.1, 3 . 31 Ibid., p. 35-37.

32 Pour un inventaire des découvertes de vaisselle à pâte blanche, voir D. TALBOT-RICE, "Byzantine Pottery *, in S. CASSON,

D. TALBOT-RICE et al., Preliminary Report upon the Excavations carried out in the Hippodrom of Constantinople in 1927 (1928), p. $29-42$; Id., * Byzantine Pottery ", in S. CASSON, D. TALBOT-RICE et al., Second Report upon the Excavations carried out in and near the Hippodrom of Constantinople in 1928 (1929), p. 22 35 ; A. OGAN, * Les fouilles de Topkapı Saray *, Belleten 4 $(1940 / 6)$, p. 239-335 ; R. B. K. STEVENSON, * The Pottery *, in G. BRETT, W. J. MACAULAY, R. B. K. STEVENSON, The Great Palace of the Byzantine Emperors, being a First Report on the Excavations carried out in Istanbul on Behalf of the Walker Trust (The University of St. Andrews) 1935-1938 (1947), p. 29-63; O. KOYUNoǦLU, « Byzantine Pottery from the Palace of Justice. Excavations at Istanbul x, Annual of the Archaeological Museum of Istanbul 18 (1953/5), p. 40-41; R. NAUMANN, H. BELTING, - Die Euphemia Kirche am Hippodrom zu Istanbul und inre Fresken ", IstForsch 25 (1966), p. 89-93; A. SABUNCU, "Pottery at Dumbarton Oaks : Note on Ceramics (from Kalenderhane Camii) •, DOP 20 (1975), p. 315-317; U. PESCHLOW, G. et S. SıISMANOĞLU, * Byzantinische Keramik aus Istanbul. Ein Fundkomplex bei der Irenenkirche ", MDAI(I) 27-28 (1977-78), p. $363-414$; J. W. HAYES, * The Excavated Pottery from the Bodrum Camii ", in C. L. STRIKER, The Myrelaion (Bodrum Camii), Istanbul (1981), p. 36-41.

33 F. MiKLOSICH, I. MuLLeR (éds), Acta et Diplomata Graeca Medii Aevi Sacra et Profana III (Vindonbonae, 1865 ; réimpr. Athènes, s.d.), p. 55.

34 Le document a été rédigé en latin en mai 1192 puis traduit en grec en octobre 1202.

35 La version latine étant : * a medio templo versus occidentem indutis testis de Nicomedia ". Testis signifie ceramique.

36 Pour les diverses interprétations, voir R. B. MASON, M. MUNDELL MANGO, "Glazed "Tiles of Nicomedia" in Bithynia, Constantinople and Elswhere ", in C. MANGO, G. DAGRON (éds), op. cit. (supra, n. 7), p. 322-323.

37 D. TALBOT-RICE, * Byzantine Polychrome Pottery. A Survey of Recent Discoveries ", CArch 7 (1954), p. 74-75. 
de vases rejetés en cours d'élaboration et la présence dans les environs d'Iznik de gisements d'argile banche, bien que cet indice ne soit pas décisif en l'état actuel des recherches ${ }^{38}$, prouvent l'existence d'ateliers en activité à Nicée durant cette période. Compte tenu de cette nouvelle donnée, l'attribution, généralement admise depuis la période byzantine, à Nicomédie, d'une fabrication de céramique à pâte blanche semble pour le moins discutable. Cette confusion se serait d'ailleurs reproduite à l'époque ottomane, comme on peut le constater à travers le témoignage du voyageur Hans Dernschwan ${ }^{39}$ qui, en 1555 , note qu'à Nicomédie/Izmit on produit de la céramique à glaçure, des coupes et des chopes qui sont largement commercialisées en Turquie. Il décrit une longue rue pleine d'artisans et d'échoppes. Or à ce moment-là, le monopole de la production du type de céramique qu'il décrit est, par rescrit impérial, attribué à Iznik ${ }^{40}$. En outre, nous savons qu'avant d'arriver à Izmit, il a passé plusieurs jours à Iznik. La confusion semble ici évidente.

\section{Les pâtes rouges}

Les vases rejetés en cours d'élaboration trouvés à Iznik ne sont pas seulement à pâte blanche, on en trouve aussi plusieurs à pâte rouge ( $\left.\mathrm{n}^{05} 63,65-67,107-108\right)$. Les particularités décoratives et morphologiques du matériel associées à ces ratés de cuisson permettent de définir les productions locales et de distinguer les céramiques dont l'origine est incertaine, quelles que soient leurs techniques de fabrication.

On trouve, parmi ce matériel, toutes les principales techniques de décoration des pâtes, tels que l'incision, le champlevé, la peinture à l'engobe et la glaçure simple. L'ensemble n'est pas homogène et l'on distingue des vases isolés et des groupes partageant - quels que soient les traitements de surface - des caractéristiques communes qui sont :

- une pâte argileuse, bien épurée - suffisamment pour permettre de tourner des vases avec des parois de 2, 3, ou $4 \mathrm{~mm}$ d'épaisseur - , fine, de couleur orange, parfois rouge brique. Bien cuite, très dure, elle a une sonorité claire;

38 Le voyageur anglais Covel signale l'existence de carrières à Ömerli: "On trouve cette terre dans des carrières sur les flancs des collines à une heure et demie à l'Est de la ville vers Homarcui... Cette terre est blanchâtre, très fine et plus farineuse que graveleuse, elle peut passer pour une sorte de terra sigillata », dans RABY, Description, p. 160, 182. Si les découvertes de terrain confirment bien l'existence, à quinze minutes de marche au Nord-Ouest d'Ömerli, de ces gisements de terre blanche, des analyses effectuées sur des échantillons prélevés indiquent que cette terre ne pouvait être employée dans la fabrication des poteries. II s'agit, en effet, de calcaire pur, inapte au façonnage: R. B. MASON, M. MUNDELL MANGo, loc. cit. (supra, n. 36), p. 323. Un gisement d'argile blanche est signalé à Karacalar au village de Verdlü, près de Lefke, mais malheureusement on ne sait rien de la qualité de cette argile : N. ATASOY, J. RABY, Iznik, p. 51 ; RABY, Description, p. 182; R. ANHEGGER, "Quellen zur osmanischen Keramik ", in K. OTTODORN, Das Islamische Iznik (1941), p. 177 n. 25. Des analyses de pâte faites à partir des ratés de cuisson et des vases découverts en fouille à Iznik, caractérisant l'argile employée, permettraient de définir exactement les productions à pâte blanche de Nicée.

$39 \mathrm{H}$. DERNSCHWAM, Tagebuch einer Reise nach Konstantinopel und Kleinasien (1923), p. 238.

40 N. ATASOY, J. RABY, Iznik, p. 23-32. 
- des vases souvent de petite taille avec des parois très fines. Ce sont majoritairement des formes ouvertes, petites coupes montées sur une base annulaire évasée caractéristique. Avec un diamètre inférieur moyen de $60 \mathrm{~mm}$ pour une hauteur de $11 \mathrm{~mm}$, une majorité de pieds se distingue par le profil intérieur courbe de la base annulaire. Cette forme n'est pas propre à une technique puisqu'on la retrouve sur des vases incisés et peints à l'engobe. Les bords sont, le plus souvent, dans le prolongement de la pansc. Les panscs sont courbcs, celles marquées par un point d'inflexion sont rares. On note quelques particularités sur certaines d'entre elles comme deux bourrelets en forme d'amande qui font probablement usage d'anses sur un des vases en vitrine, ou des bandes en relief appliquées donnant l'illusion de godrons $\left(\mathrm{n}^{\circ} 18\right)$, ou encore deux panses aux parois ondulées, enfoncées régulièrement au pouce $\left(n^{\text {os }} 56-57\right)$;

— un engobe blanchâtre ou rosé ;

- l'utilisation de la pernette est attestée par les fréquentes traces observées, pieds arrachés ou arrachement de la glaçure;

- une des principales particularités de cette production est l'emploi d'une glaçure plombifere très brillante de couleur orange. Recouvrant la majeure partie des vases, elle côtoie des glaçures vertes - vert pâle ou vert bouteille - et des glaçures jaunes - jaune pâle ou jaune d'or - auxquelles elle est parfois associée sur un même objet.

\section{A. La céramique incisée}

1. Un groupe très homogène et très représenté est sans ambiguïté une production locale. Dans les vases de ce groupe, l'incision est associée au champlevé afin de réaliser une série de décors dont les principales caractéristiques sont les suivantes. Le motif le plus fréquent est un oiseau, généralement figuré de profil, tourné indistinctement vers la droite ou la gauche $\left(\mathrm{n}^{\text {os }} 18-23\right)$. Il se distingue des nombreuses représentations de volatiles ${ }^{41}$ fréquentes sur les vases byzantins, par son gros œil rond, la forme de son bec et surtout par la série de gouttelettes qui s'en échappent. Cet oiseau est placé dans un médaillon central, souvent délimité par deux cercles concentriques formant un bandeau orné de spirales seules ou de spirales alternant avec des chevrons ou des bandes verticales champlevées. Ce médaillon peut également constituer le centre d'une fleur sophistiquée. Quelques rares exemplaires montrent un oiseau aux ailes déployées représenté de face, très grossièrement stylisé ( ${ }^{\text {os }}$ 24-25). La composition peut être complétée par l'observation des vases

41 Sur divers types d'oiseaux, voir C. NICOLESCU, " La céramique à vernis plombeux des $x^{e}-x v^{e}$ siècles dans les pays roumains ". Faenza 5-6 (1965), p. 105, pl. LXII et p. 107, fig. 2, pl. LXV; S. GEORGIEVA, "Keramika bitovi predmeti nakiti i tukani ", Carevgrad Tarnov. Le palais des rois bulgares pendant le deuxième royaume bulgare (XIF-XIve siècles) (1974), p. 105-108, fig. $71-74$ et p. $112-118$; C. BAKIRTZIS, D. PAPANIKOLA-BAKIRTZIS, - De la céramique byzantine en glaçure à Thessalonique ", Byzantina-Bulgarica 7 (1981), p. 434-435, fig. 19-21; V. FrançoIs, La céramique byzantine à Thasos, Etthas XV (1995), p. 87-88. 


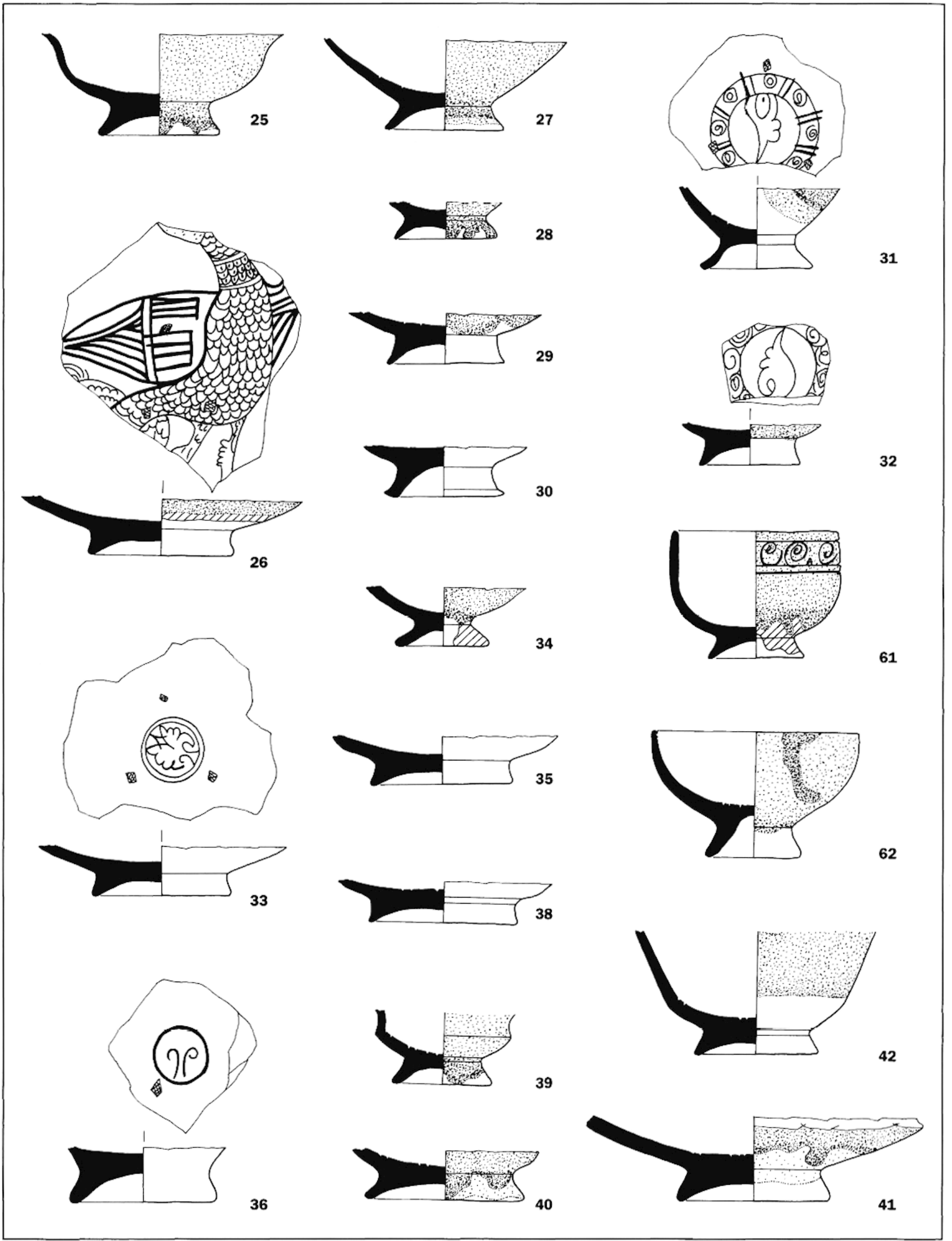

Fg. 3. Céramique incisée (1: 3). 

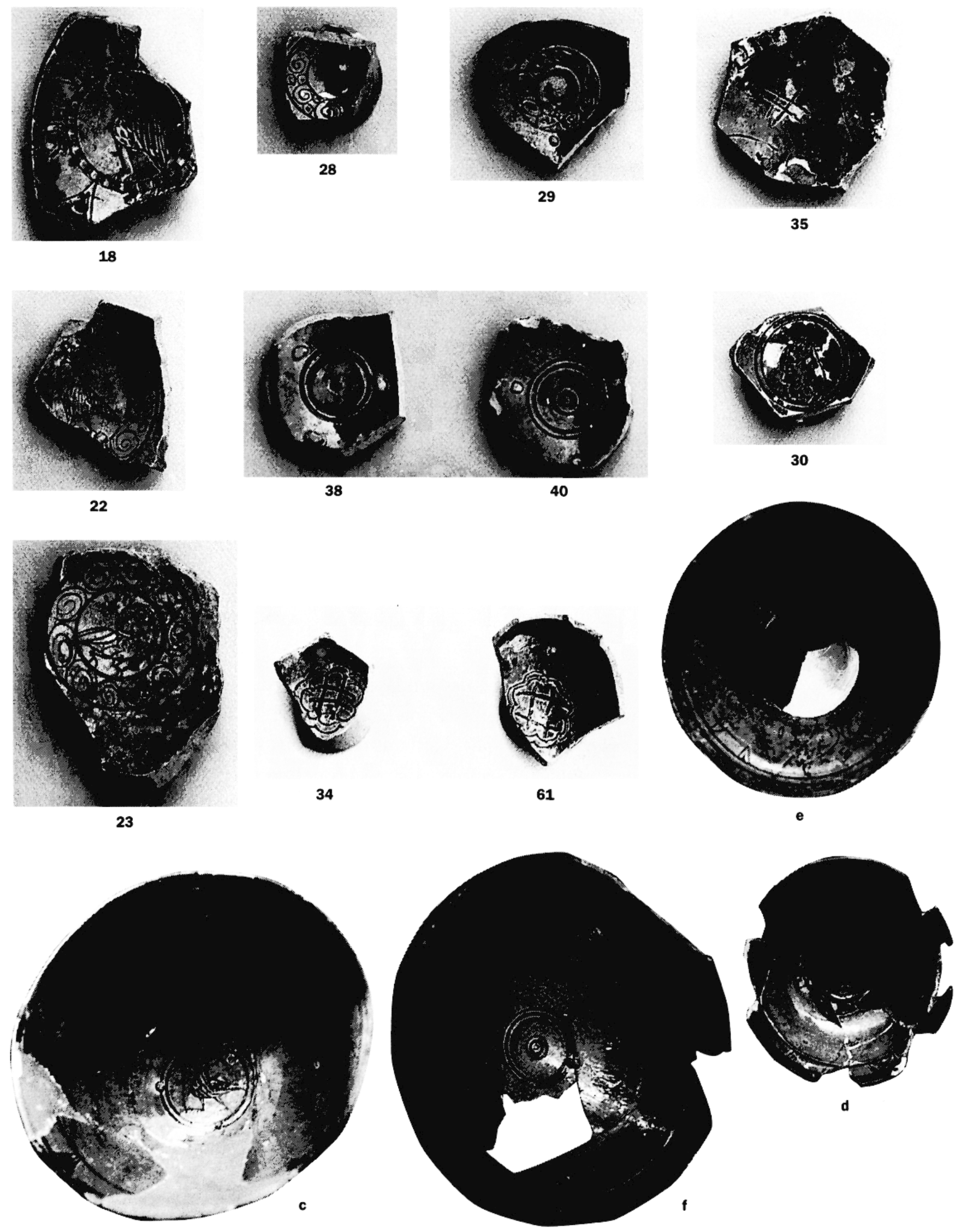

Fig. 4. Céramique incisée. 
entiers $^{42}$ : médaillon central avec l'oiseau, et cercles concentriques sur le bord formant un bandeau orné soit de chrevrons imbriqués régulièrement espacés, soit de spirales (fig. 4c). La glaçure plombifere est vert pâle, jaune clair ou orange. Le seul exemplaire semblable, découvert hors de Bithynie, est un vase de Chersonèse qui possède exactement ces caractéristiques. Il est daté des XIII ${ }^{e}-\mathrm{XIV}^{e}{ }^{\mathrm{s}} .^{43}$.

Les autres décors fréquents sont:

- un médaillon central délimité par deux cercles concentriques formant un bandeau orné de spirales, parfois incisées sans soin $\left(\mathrm{n}^{\text {os }} 27-29\right)$;

- une palmette ou une demi-palmette incisée dans un médaillon central plus ou moins sophistiqué ( ${ }^{\text {os }} 30-33$ ). Trois exemplaires complets de ce type sont exposés au musée : à partir du médaillon orné d'une palmette se développent, sur la panse, des bandes rayonnantes remplies de spirales, alternant avec des tiges fleuronnées ou encore des palmettes et des fleurons alternés; la glaçure est orange (fig. 4d-e) ;

- une double croix incisée dans une double fleur au fond du vase ( $\mathrm{n}^{\text {os }} 34-35$, 61) ;

- deux traits rectilignes terminés par une boucle et des croix ou des étoiles placées au centre de motifs fragmentaires ( $\mathrm{n}^{\text {os }}$ 36-37);

- enfin, dans la même série, plusieurs fonds sont décorés de simples cercles concentriques incisés et champlevés $\left(\mathrm{n}^{\text {os }} 38-43\right)$. Les glaçures sont orange et exceptionnellement vert bouteille. Un vase complet du musée porte le même décor (fig. 4f).

Les bords correspondant à ces fonds sont incisés de cercles concentriques plus ou moins nombreux associés parfois à une ligne ondulée ( $n^{\text {os }} 46-57$ ), ou encore ornés de spirales tracées avec soin ( $n^{\circ} 58$ ). Certains d'entre eux possèdent un décor à l'extérieur : rinceaux de spirales incisées ou champlevées entre cercles concentriques; bandeau de hachures ou bandeau de traits verticaux.

2. Un second groupe à pâte rouge, incisé, mais d'un style beaucoup moins homogène que le précédent, semble lui aussi d'origine nicéenne:

- un vase décoré d'un grand oiseau ( $\left.{ }^{\circ} 26\right)$ d'un genre différent des précédents se rattache, par sa pâte et la forme de son pied, aux groupes déjà mentionnés;

- un morceau de panse à glaçure orange couvert de points incisés profondément est sans doute le fragment d'un grand félin tacheté comme celui dessiné sur un vase complet du musée, couvert d'une glaçure de même couleur (fig. $7 \mathrm{~g}-\mathrm{h}$ ). Plusieurs tessons mouchetés analogues, mais cette fois à glaçure verte, ont été retrouvés dans les fouilles du Théâtre ;

- différentes représentations figurées apparaissent également au musée, au Théâtre et dans les fouilles des ateliers ottomans. Sur un grand fragment, à pâte fine, 


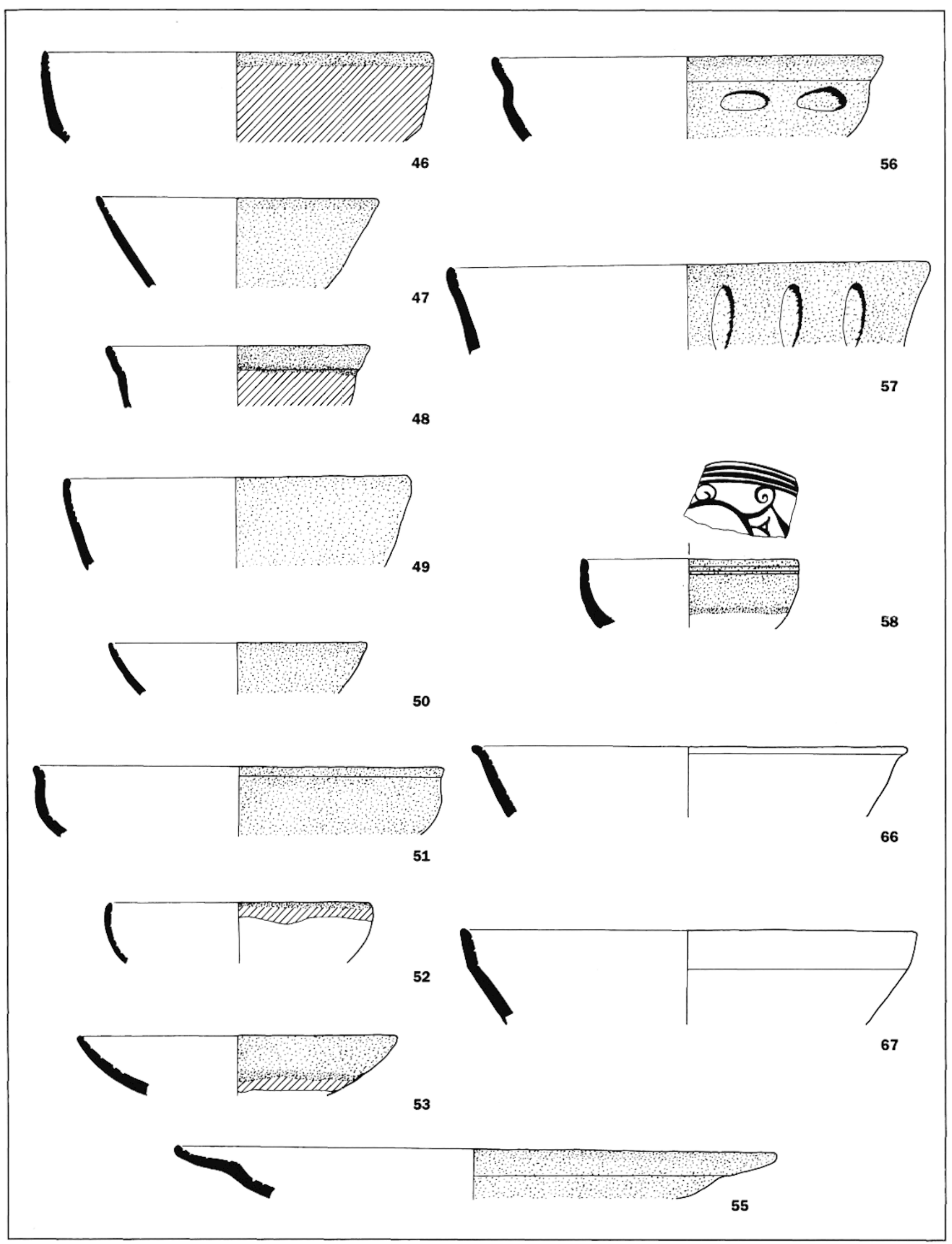

Flg. 5. Céramique incisée $(1: 3)$. 
orange vif, un homme de face, vêtu d'une jupe et d'un pourpoint orné de spirales, les bras écartés, semble tenir un bouclier; autour de lui quelques arbres et fleurons stylisés. Ce décor, où incisions et champlevé se combinent, est d'une très grande qualité d'exécution. La glaçure est jaune brun à l'intérieur et verte à l'extérieur. La forme du pied est identique à celle du groupe déjà cité. Sur un autre fond, c'est un joueur de luth représenté de face qui est incisé sous une glaçure verte. Un combat entre un félin et un homme chaussé de souliers à la poulaine est incisé à travers une couche d'engobe sur le fond et le bas de la panse d'un vase de grandes dimensions. La glaçure est vert pré. Enfin, un petit personnage brandissant une épée est dessiné très grossièrement dans un médaillon central, sous une glaçure jaune pâle.

La pâte de nature identique, la forme du pied, les tailles proches, la couleur de la glaçure, l'homogénéité de style et la quantité de vases au même décor attestent une origine commune pour tous ces vases. Mais ce qui témoigne incontestablement d'une production locale, c'est la découverte de ratés de cuisson et de vases rejetés en cours d'élaboration (fig. 2). Ainsi, on trouve un bord couvert d'engobe, incisé de cercles concentriques et d'une ligne ondulée, déformé après la première cuisson et deux autres petits fragments de bords au même décor, rejetés avant d'avoir reçu la glaçure ( $\mathrm{n}^{\text {os }} 66$ 67). Un fond appartenant à la série des demi-palmettes a été jeté après la première cuisson, incisé mais pas glaçuré $\left(\mathrm{n}^{\circ}\right.$ 63), et une autre base à la forme caractéristique, surcuite après la seconde cuisson, a également été écartée ( $\mathrm{n}^{\circ}$ 65).

Par plusieurs de ses aspects, cette production bithynienne est très proche de la Zeuxippus Ware ${ }^{44}$ dont un certain nombre d'exemples ont été découverts à Iznik. II s'agit d'un fond orné de cercles concentriques incisés et excisés, à glaçure jaune clair brillante ( $\mathrm{n}^{\circ}$ 68), typique de la classe IA de A. H. S. Megaw ${ }^{45}$. C'est à la classe II caractérisée notamment par des vases ornés de représentations figurées telles que Digenis Akritas, Saint-Georges combattant le dragon, diverses scènes de chasse et quelques animaux fantastiques, vases retrouvés en Chersonèse ${ }^{46}$ - que se rattachent trois tessons d'Iznik ( $\mathrm{n}^{\text {os }} 71-73$ ), trop fragmentaires pour que l'on puisse identifier précisément la scène représentée. Enfin, deux vases à bandeaux excisés remplis de points peints à l'engobe, à glaçure orange ou jaune clair $\left(n^{\text {os }}\right.$ 69-70), sont des exemplaires de la classe IB $^{47}$, identiques à des fragments retrouvés à Paphos dans le château de Saranda Kolones ${ }^{48}$, dans les fouilles sur l'emplacement de l'ancien jardin botanique à Istanbul ${ }^{49}$ et à Alexandrie ${ }^{50}$. Il n'y a rien de très étonnant à trouver ces exemplaires de Zeuxippus Ware

44 Céramique qui tire son nom du premier lieu de découverte: les Thermes de Zeuxippe à Constantinople, trouvés en 1927 par la British Academy lors des campagnes de fouilles de I'Hippodrome. D'abord isolée par D. Talbot-Rice sous le nom de Shiny Olive Incised Ware, cette production est véritablement mise en évidence par A. H. S. Megaw en 1968, qui distingue deux classes principales. Cf. D. TALBOT-RICE, « Byzantine Pottery *, in S. CASSON, D. TALBOT-RICE et al., Preliminary Report upon the Excavations carried out in the Hippodrom of Constantinople in 1927 (1928), p. 34 ; MEGAW, Zeuxippus Ware, p. $67-88$.

45 ibid., p. 69-70.

46 A. L. YAKOBSON, "Ceramics and Ceramic Production in Medieval Crimea *, Studia Albanica (1979), pl. 74.5, 75-77, 79.4. 47 MEGAW, Zeuxippus Ware, p. 71.

48 Ibid., p. 85-86, pl. 21c. 


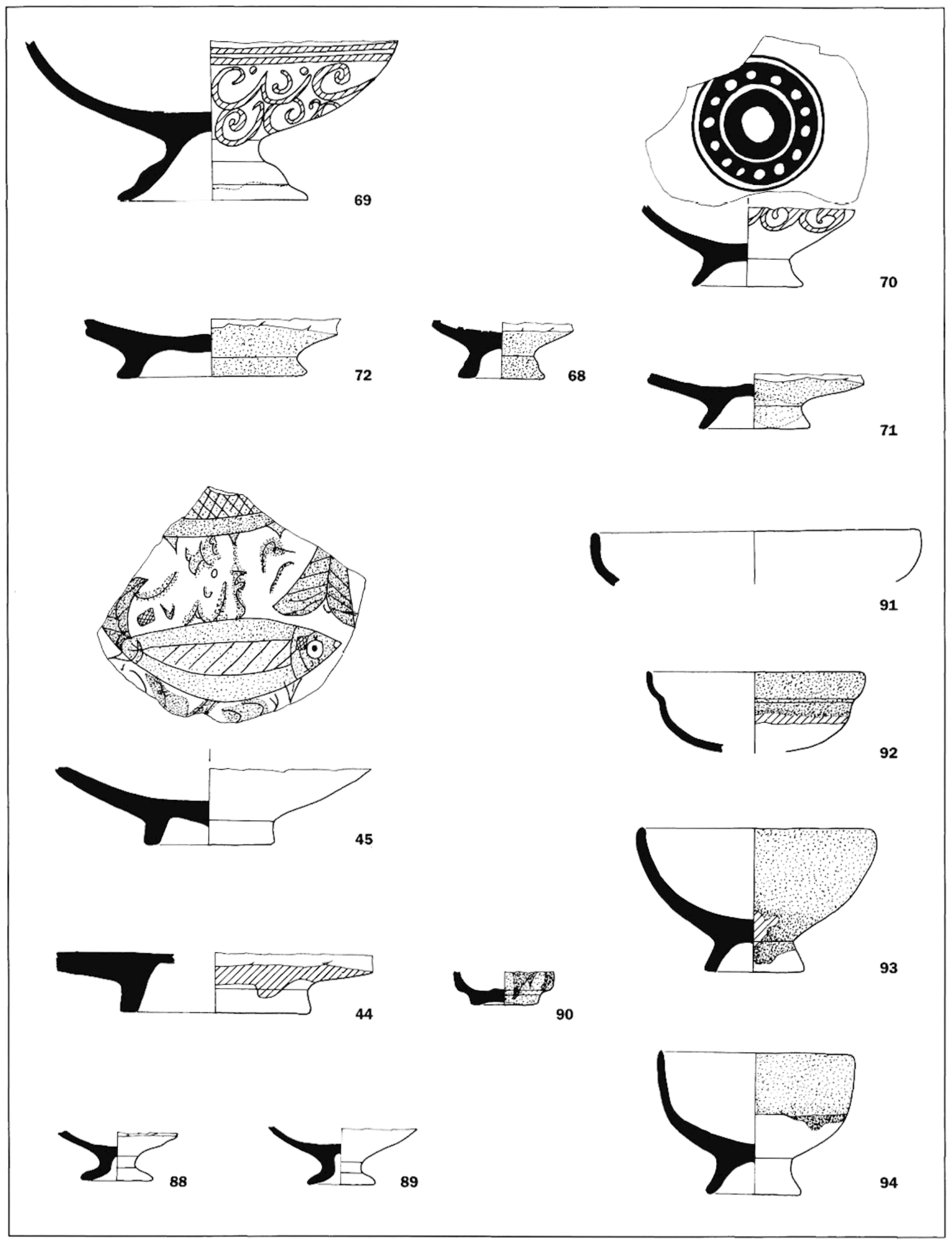

Fig. 6. Zeuxippus Ware ( $n^{\circ 5}$ 68-72), céramique incisée $\left(n^{\circ 5} 44-45\right)$ et céramique à glaçure monochrome ( $\left.n^{\circ 5} 88-94\right)(1: 3)$. 


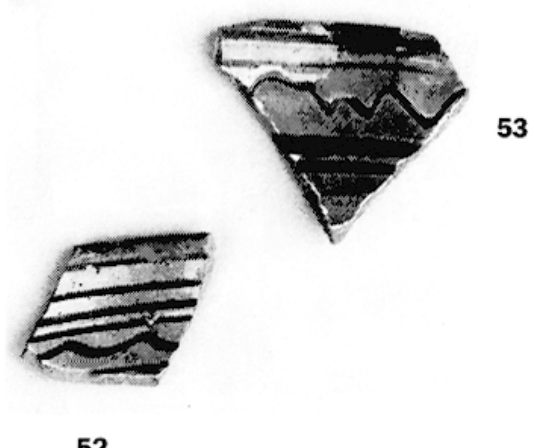

52

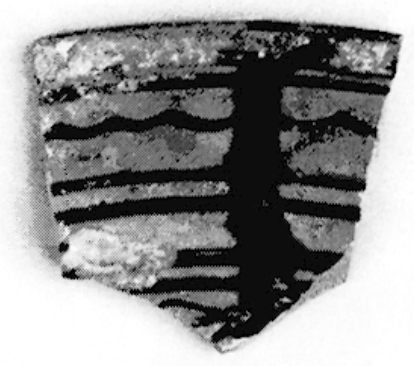

55

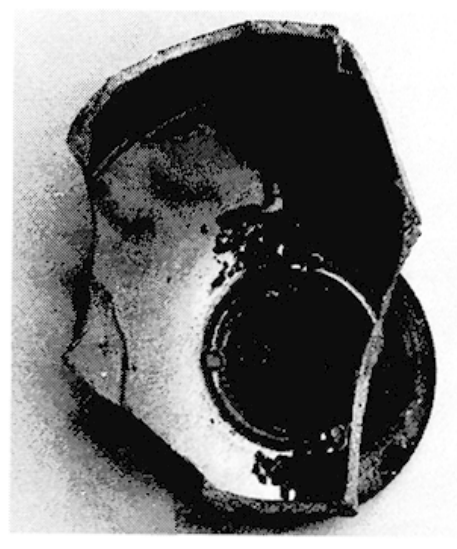

69 int.

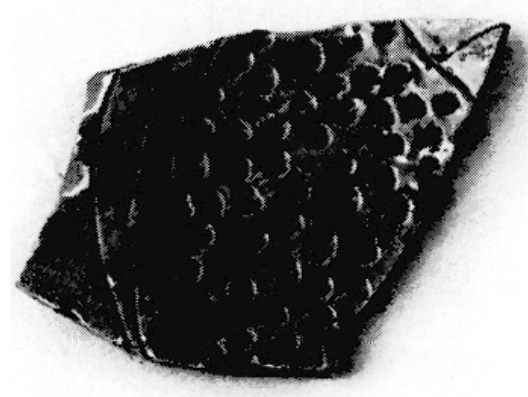

h

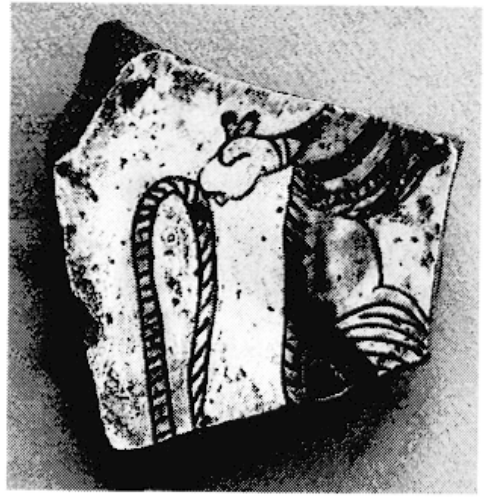

71

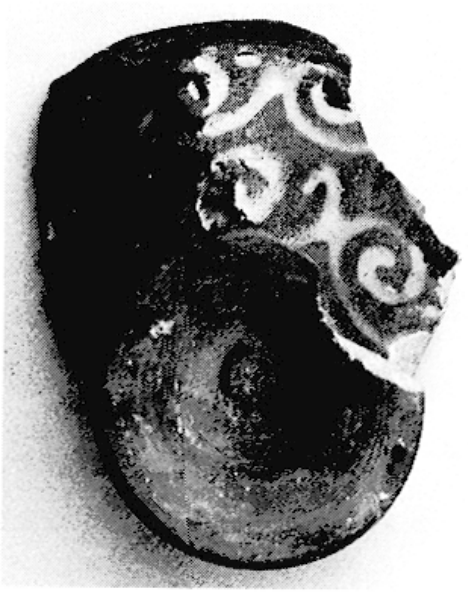

69 ext.
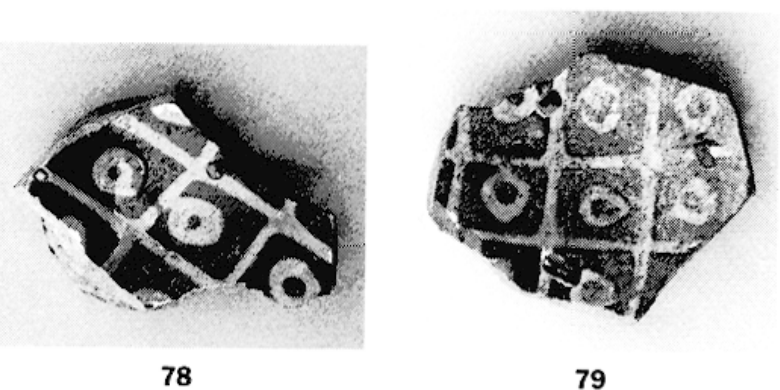

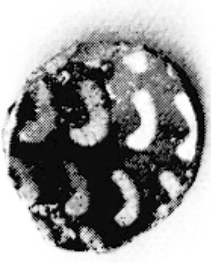

80

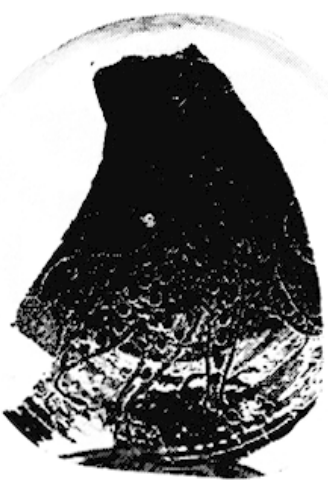

g

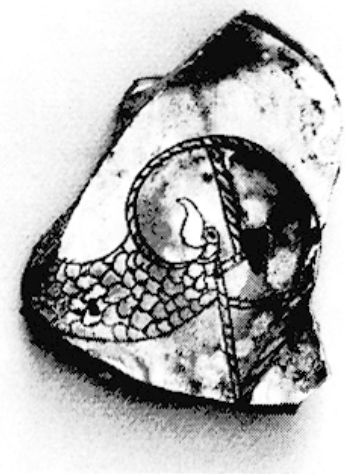

72
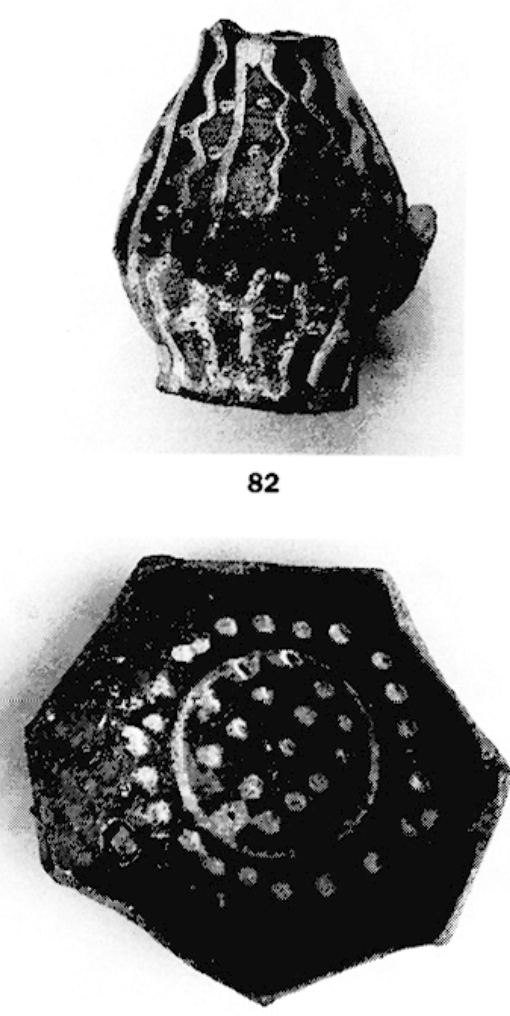

75

Fig. 7. Céramique incisée ( $\left.n^{\circ s} 52-55, \mathrm{~g}, \mathrm{~h}\right)$, Zeuxippus Ware $\left(\mathrm{n}^{\circ \mathrm{s}} \mathbf{6 9}, \mathbf{7 1 - 7 2}\right)$ et céramique peinte à l'engobe $\left(\mathrm{n}^{\circ \mathrm{s}} \mathbf{7 5}, \mathbf{7 8 - 8 0}, \mathbf{8 2}\right)$. 
à Iznik, dans la mesure où cette céramique, datée de la fin XII ${ }^{e}$-début XIII ${ }^{e}$ s., a été très largement distribuée dans l'empire byzantin et en dehors de ses frontières ${ }^{51}$. Les vases classés par A. H. S. Megaw en Zeuxippus Ware classe IB - vases ornés de cercles concentriques ou de bandeaux de spirales incisés sous une glaçure orange, classe établie à partir des fragments découverts dans les fouilles de Saraçhane ${ }^{52}$, dans les citernes de Gulhané dans le quartier des Manganes ${ }^{53}$, et dans les fouilles de Kalenderhane Camii dont le matériel est daté des environs de $1220^{54}$ — présentent à première vue plusieurs caractéristiques communes à une part importante de la production nicéenne à pâte rouge. Cependant, le type Zeuxippus Ware IB est élaboré par l'agrégation, sur la base de la couleur de leur glaçure, de vases qui présentent par ailleurs de fortes différences, notamment dans leurs formes et dans leurs décors ${ }^{55}$. On peut en fait distinguer deux types dont un, le mieux représenté, s'apparente aux vases nicéens ( $\mathrm{n}^{\text {os }} 27$ 29, 38, 40-42). Malgré ces homologies, la production nicéenne comprend aussi des vases dont le décor ou bien le traitement de surface ne relèvent absolument pas de la Zeuxippus Ware Family. Convient-il alors d'élargir la Zeuxippus Ware, catégorie déjà très variée, en y rattachant les divers types bithyniens, ou au contraire de revoir la typologie mise en place par A. H. S. Megaw et de l'affiner en excluant les vases qui se rattachent beaucoup mieux à une des productions nicéennes du XIII $s$. ?

\section{B. La céramique peinte à l'engobe}

La céramique peinte à l'engobe est à Iznik tout à fait particulière. En effet, ses décors ne se rattachent à aucun type habituellement rencontré. Damier dont chaque case est orné d'un cercle, succession de virgules ou encore cercles soulignés ou remplis de semis de points peints à l'engobe constituent les motifs principaux des vases ouverts ( $\mathbf{n}^{\text {os }} 74-80$ ). La glaçure est orange, jaune d'or, jaune pâle ou pistache. Les vases sont de toutes tailles - $250 \mathrm{~mm}$ de diamètre pour le plus grand et $140 \mathrm{~mm}$ pour le plus petit - mais le profil des pieds est conforme au type habituel, de même que la pâte. A l'extérieur, de grands cercles sont souvent peints sur la panse. Deux cruches ( ${ }^{\text {os }}$ 82-83), ornées de lignes verticales ondulées alternant ou non avec des lignes de points, complètent les découvertes de cette catégorie réalisée elle aussi à Nicée.

49 J. EBERSOLt, Catalogue des poteries byzantines et anatoliennes du Musée de Constantinople (1910), p. $18 n^{\circ} 38$. $50 \mathrm{~V}$. FrançoIs, La céramique médiévale à Alexandrie. Contribution à l'histoire économique de la ville, Études Alexandrines 2 (sous presse).

51 Pour une carte de distribution mise à jour, voir V. FRANÇOIS, - Sur la circulation des céramiques byzantines en Méditerranée orientale et occidentale ", Actes du V Congrès international sur la céramique médiévale en Méditerranée, Aixen-Provence, 13 18 novembre 1995 (1997), p. 231-236.

52 A. H. S. MEGAW, "Zeuxippus Ware again ", in V. DÉROCHE, J.-M. SPIESER (éds), Recherches sur la céramique byzantine, BCH Suppl. XVIII (1989), p. 260-262, fig. 2.
53 R. DEMANGEL, E. MAMBOURY. Le Quartier des Manganes et la première région de Constantinople (1939), p. 137, fig. 184.3; MEGAW, Zeuxippus Ware, p. 75, fig. 2 n 5449, pl. $15 e$; Id., loc. cit. (supra, n. 52), fig. 4.

54 Datation établie à partir de la découverte d'une petite coupe de ce type associée à une monnaie. Par ailleurs, aucun exemplaire de ce genre n'apparaît dans les dépôts associés avec le bâtiment de l'église principale, alors qu'ils sont fréquents dans les niveaux en relation avec le réaménagement du diaconicon durant l'occupation latine. A. H. S. MEGAW, loc. cit. (supra, n. 52), p. 261. 55 MEGAW, Zeuxippus Ware, p. 71. 


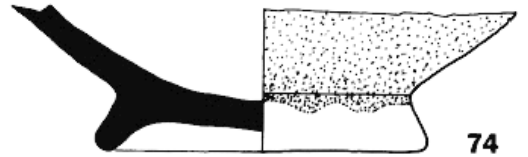

74

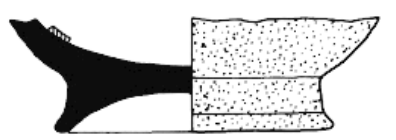

75

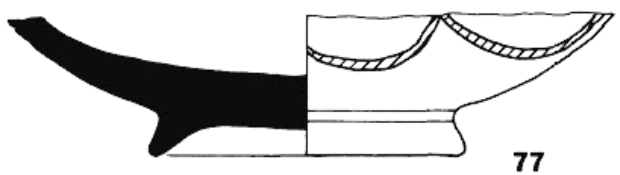

77
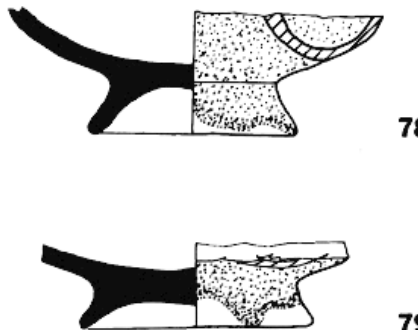

79

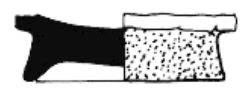

80

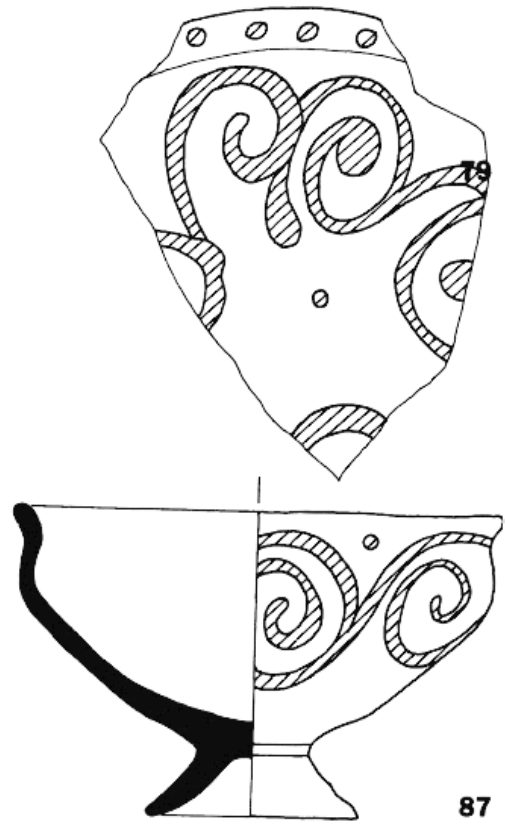

87

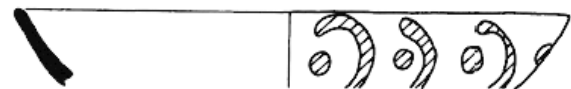

86

85

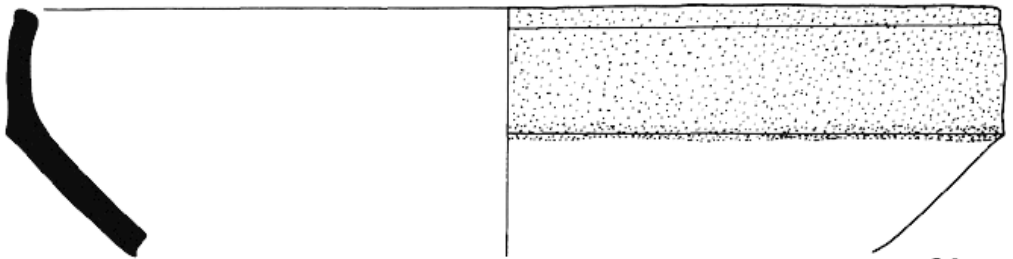

84

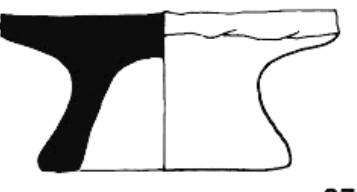

97
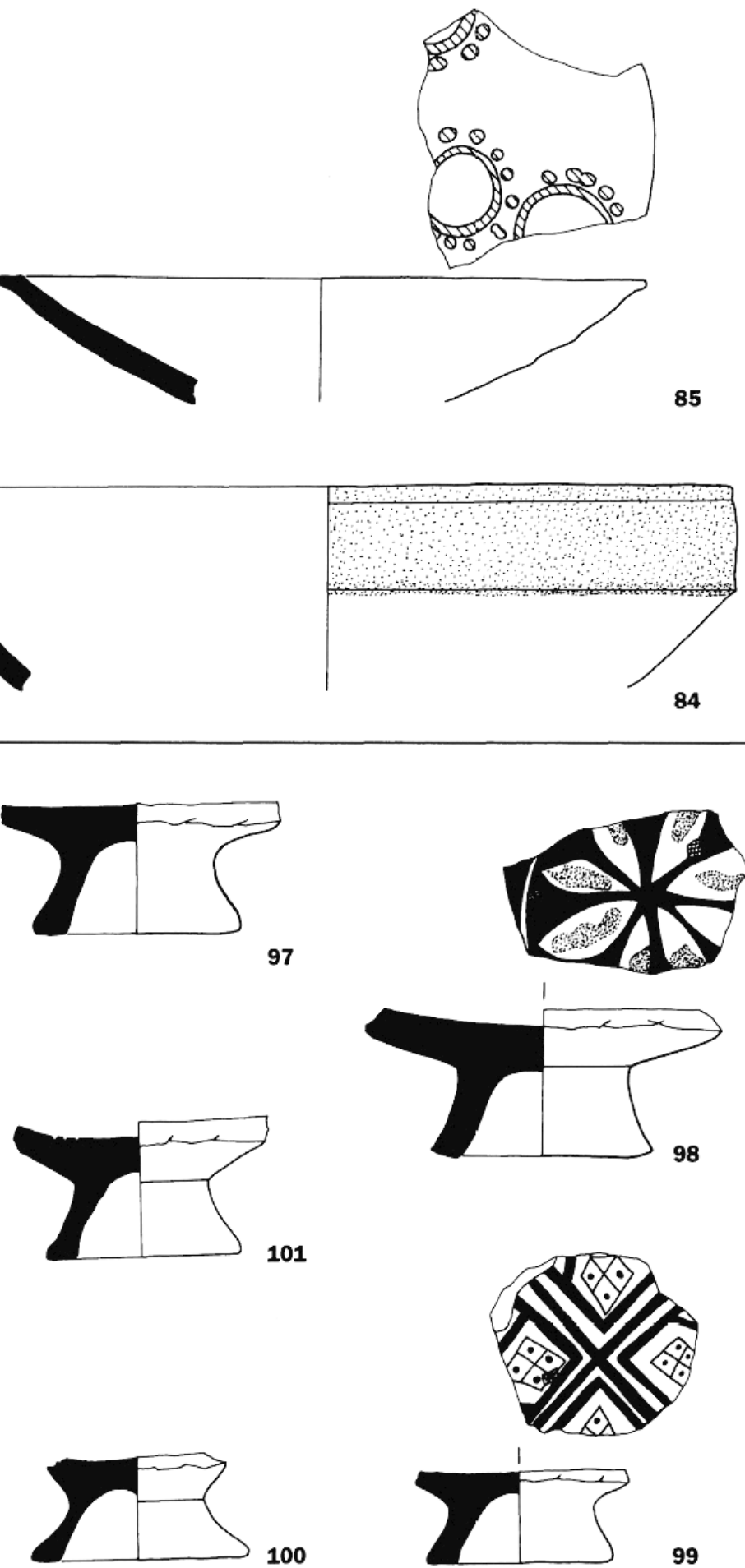

101

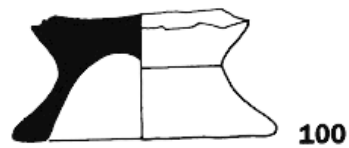

98

99

Fig. 8. Céramique peinte à l'engobe ( $n^{\circ s} 7475,77-80,8487$ ) et céramique champlevée ( $n^{\circ 5}$ 97-101) $(1: 3)$. 


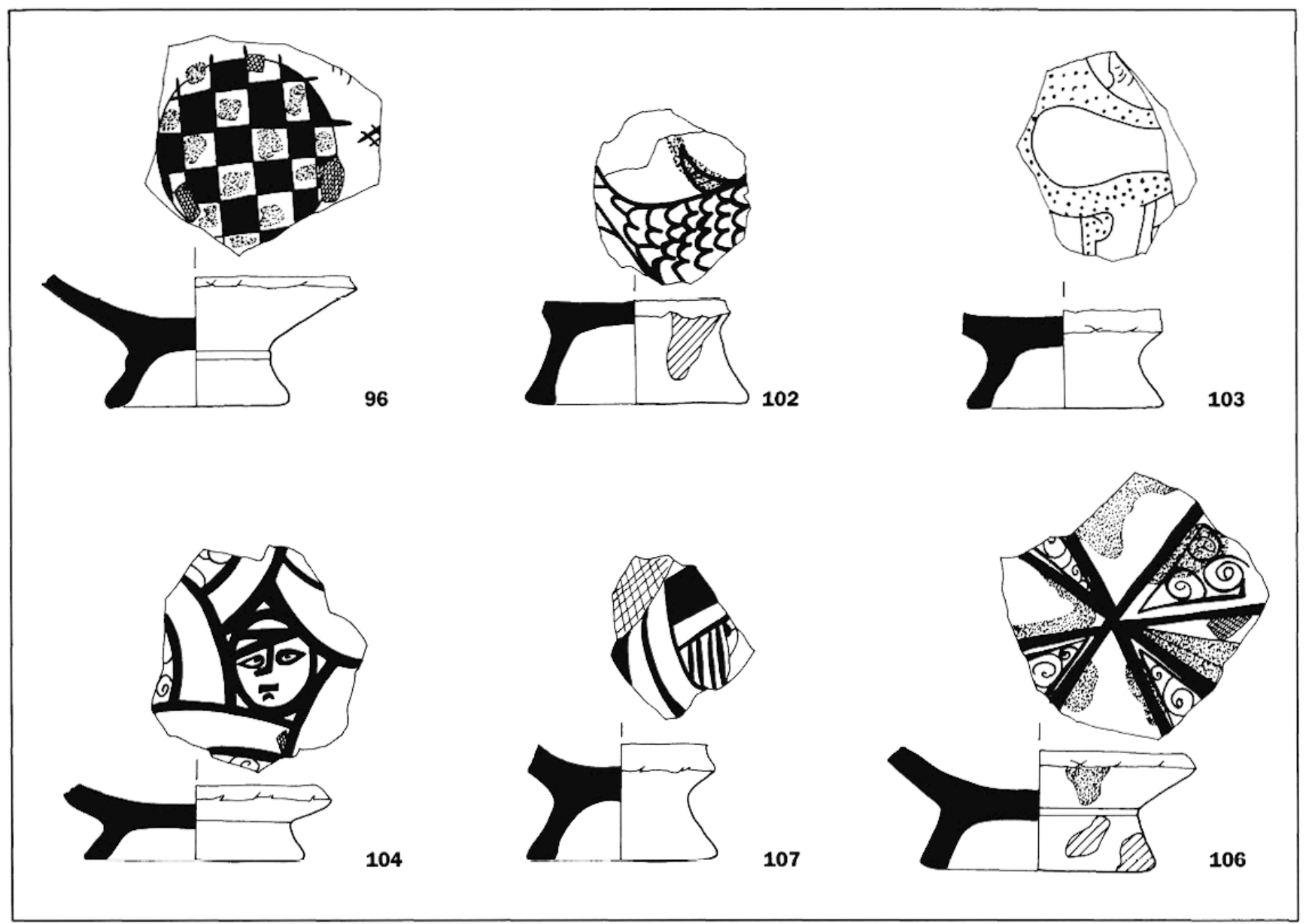

Fig. 9. Céramique champlevée (1: 3).

\section{La céramique champlevée}

S'il est difficile d'attribuer avec assurance aux ateliers de Nicée tous les vases champlevés présentés ici, il existe des preuves d'une production locale pour certains d'entre d'eux. Le premier, un fond orné d'un oiseau dont il ne subsiste que l'aile, n'est pas sans rappeler "l'oiseau de Thessalonique" ( $\left.n^{\circ} 95\right)$. Le traitement de cet oiseau champlevé et incisé est caractéristique et il a été attribué aux ateliers thessaloniciens du XIVe s., grâce, notamment, à la découverte dans cette ville de déchets de cuisson ${ }^{56}$. Cet exemplaire n'est pas unique à Iznik, puisque les fouilles du Théâtre ont livré un fragment encore plus proche du modèle initial. Mais il est peu probable que ces vases viennent de Macédoine, car un fond du même genre, surcuit, décoré d'une aile fragmentaire en partie recouverte des restes d'un vase collé, apparaît parmi le matériel de la Poste $\left(\mathrm{n}^{\circ}\right.$ 107). On peut donc considérer Nicée comme un autre centre producteur du fameux oiseau : il reste à savoir si cette production est antérieure à celle de

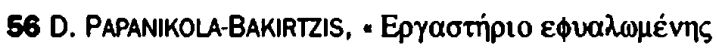

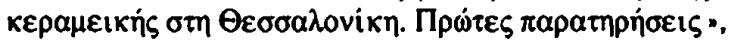
Makedonia. Mélanges Styl. Pélékanidis 5 (1983), p. 377-388. 


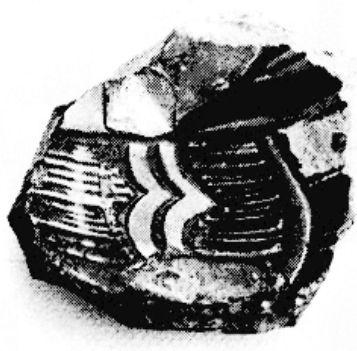

95

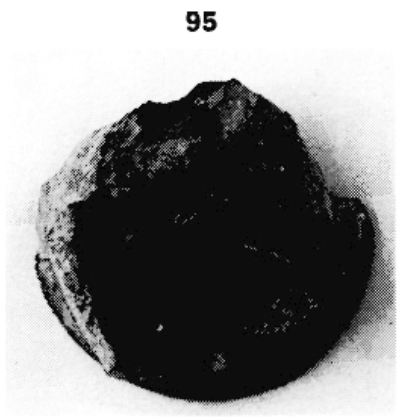

107

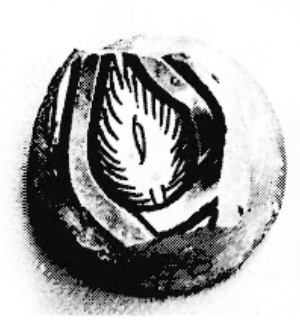

100

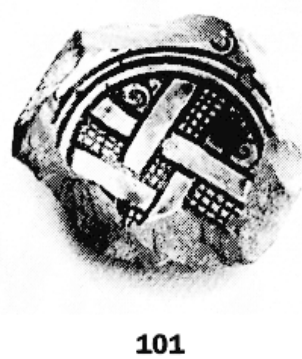

101

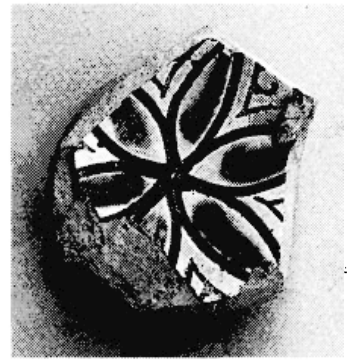

97

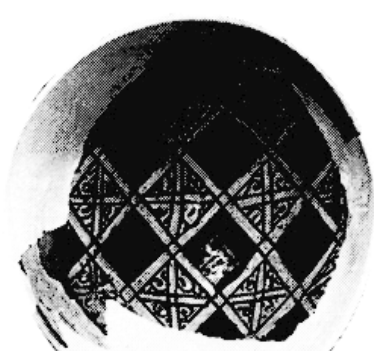

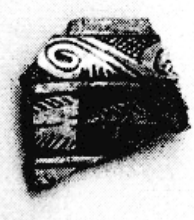

105

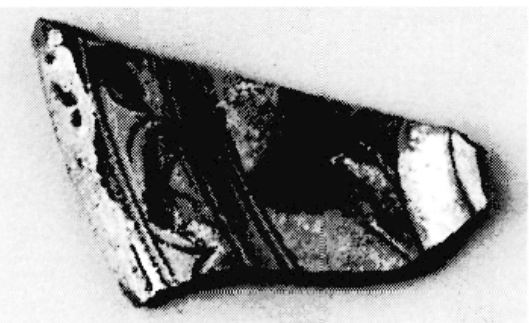

60

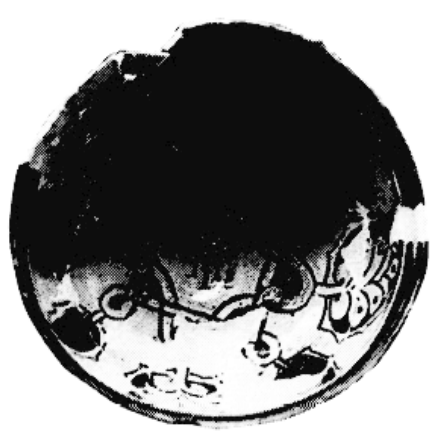

j

Fig. 10. Céramique champlevée de production locale ( $\left.n^{\circ 5} 95,97,100-101,107\right)$, céramique importée $\left(n^{\circ} 105, I, j\right)$ et céramique incisée importée $\left(n^{\circ} 60\right)$.

Salonique ou contemporaine. Parmi les autres vases traités au champlevé, on distingue une série de huit fonds assez homogène d'un point de vue morphologique et décoratif $\left(\mathrm{n}^{\text {os }}\right.$ 96-103). La forme du pied est identique à celle des fragments précédents réalisés à Nicée : pied haut, largement évasé à la base et au diamètre supérieur réduit, hauteur comprise entre 17 et $26 \mathrm{~mm}$, pour un diamètre compris entre 57 et $68 \mathrm{~mm}$. Les décors divers - damier, fleur, losanges, petit arbre, bandes entrelacées, poisson exécutés avec soin sont systématiquement rehaussés de pigments verts sur une glaçure jaune pâle. La pâte est fine, orange ou rouge. Ce groupe homogène est donc vraisemblablement issu d'un atelier local en activité au début du XIVe $s$. Un pied déformé surcuit orné d'un damier champlevé ( $\left.\mathrm{n}^{\circ} 108\right)$ est un autre exemplaire de la production nicéenne; il n'est pas sans rappeler un fragment identique retrouvé sur l'emplacement de l'ancien jardin botanique à Istanbul ${ }^{57}$. 


\section{Les céramiques importées}

Quelques tessons ( $\mathrm{n}^{\text {os }} \mathbf{4 4 - 4 5 , 6 0 )}$ semblent assez proches de la céramique de Saint-Syméon, produire à Al Mina ${ }^{58}$ de la fin du XII à la fin du XIII $s$. La représentation de deux poissons placés tête-bêche rappelle un vase attribué à la Syrie du Nord, daté du XIII ${ }^{e} .{ }^{59}$, et une coupe découverte en Chersonèse, datée des XIII ${ }^{e}$ XIV ${ }^{e}{ }^{60}$. Plusieurs vases ( $\mathrm{n}^{\text {os }}$ 88-92) sont caractérisés surtout par leur petite taille - un diamètre supérieur compris entre 90 et $150 \mathrm{~mm}$, pour une hauteur entre 64 et $78 \mathrm{~mm}$ - et la finesse de leurs parois - $2 \mathrm{~mm}$ par exemple. Ce sont de petites coupes aux profils assez différents, $\mathrm{n}^{\circ} \mathbf{8 8}$ et $\mathrm{n}^{\circ} \mathbf{8 9}$ se faisant remarquer par un pied de forme très inhabituelle. Les glaçures monochromes, le plus souvent, appliquées sur engobe, sont colorées dans diverses tonalités de vert et de jaune ( $\mathrm{n}^{\mathrm{os}} \mathbf{8 8 - 9 2}$ ). Il est difficile de dire si ces vases ont été produits localement ou importés. Quelques fragments traités au champlevé se rattachent à diverses traditions sans pour autant y être attribués avec assurance. Ainsi, la représentation d'un visage stylisé, une sorte de face lunaire $\left(\mathrm{n}^{\circ}\right.$ 104), rappelle les productions chypriotes du XIV ${ }^{e} s$., bien que la forme du pied et le traitement extérieur de la panse soient différents ${ }^{61}$. Le vase complet présenté dans une des vitrines du musée (fig. 10i), orné d'un décor couvrant de damier dont une case sur deux est excisée et l'autre divisée en quatre par une croix incisée, couvert d'une glaçure jaune, est tout à fait identique à divers fragments datés du XIV ${ }^{e}$ s., retrouvés à Istanbul ${ }^{62}$, Caffa ${ }^{63}$ et Kaliakra ${ }^{64}$. De même, une autre coupe du musée, remarquablement conservée, possède un décor champlevé et incisé très fréquent: il s'agit d'un monogramme de Michael placé au centre d'un médaillon constitué par l'entrelacs de deux rubans, un carré aux côtés droits et un autre aux côtés concaves orienté suivant la diagonale du premier (fig. 10j). La glaçure est jaune d'or. Ce motif est caractéristique de divers vases retrouvés à Istanbul — dans les fouilles de l'Hippodrome $^{65}$ et dans les citernes de Gulhané ${ }^{66}$ - et en mer Noire à Kaliakra ${ }^{67}$. Enfin, le bord $n^{\circ} 105$ est tout à fait intéressant et exceptionnel, notamment caractérisé par des feuilles finement nervurées, traitées au champlevé, disposées horizontalement sur le bord et par des sortes de godrons excisés sur la panse à l'extérieur. Un décor absolument identique apparaît associé à un monogramme de Michael sur un vase du Louvre trouvé à Istanbul ${ }^{68}$ et il est évident que ces deux vases sont issus du même

58 A. LANE, "Medieval Finds at Al Mina in North Syria ", Archaeologia 87 (1937), p. 1961.

$59 \mathrm{~J}$. SOUSTIEL, La céramique islamique. Le guide du connaisseur (1985), p. 135, fig. 163.

60 I. S. CHICHUROV, op. cit. (supra, n. 43), p. 155 n $^{\circ} 163$.

61 A. H. S. MEGAW, J. DU PLAT TAYLOR, a Cypriot Medieval Glazed Pottery :, RDAC (1937-39) [1951], p. 3, Groupe V, pl. IX.14;

A. H. S. MEgAW, A. DikIgOROPOULOS, * Early Glazed Pottery from Polis ", RDAC (1940-48) [1958], p. 83, pl. VIIlh.

62 J. EBERSOLT, op. cit. (supra, n. 49), p. $38 n^{\circ} 148$.

63 A. SAZANOV, Y. IVASCHENKO, - Les fouilles de Caffa médiévale en 1991-1992 " [en russe], Mélanges Bosphoriens 4 (1994), p. 185 , fig. 1.
64 L. BOBCHEVA, * Sgraffito Ware at Kaliakra *, IzWVarna 15 (1979), pl. III no 30 ; M. IOSIFOVA, * Céramique à décor sgraffito de Kaliakra (XII1"-première moitié du XVe siècle) ", ByzantinoBulgarica 7 (1981), p. 441, fig. 4.

65 C'est un exemplaire d'Elaborated Incised Ware, classe IB, définie par Talbot-Rice : D. TALBOT-RICE, loc. cit. (supra, n. 44), p. 31-32, fig. 40 .

66 R. DEMANGEL, E. MAMBOURY, op. cit. (supra, n. 53), p. 143 , fig. 187.3 et p. 147, fig. 195.16 .

67 L. BOBCHEVA, loc. cit. (supra, n. 64), pl. l.1.

$68 \mathrm{Ch}$. VOGT, "Céramiques ", in Byzance. L'art byzantin dans les collections publiques françaises, Musée du Louvre, 3 nov. $1992-1^{\text {er }}$ février 1993 (1992), p. $492 \mathrm{n}^{\circ} 384$. 
centre producteur. Tous ces exemples et leurs parallèles sont généralement attribués à une production constantinopolitaine datée du XIV $s$.

L'étude des céramiques à pâte blanche et à pâte rouge découvertes à Iznik montre qu'il existait à Nicée des ateliers qui produisaient de la vaisselle de table destinée à une consommation locale et régionale ${ }^{69}$. Par ailleurs, si l'on admet que les vases à pâte blanche retrouvés en quantité, associés à des ratés de cuisson et illustrant les principales catégories de Glazed White Ware, ont tous été fabriqués à Nicée entre le $\mathrm{X}^{\mathrm{e}}$ et le début $\mathrm{du} \mathrm{XIII}^{\mathrm{e}} \mathrm{s}$., on se doit de considérer la ville comme un centre d'approvisionnement de la capitale. Les vases à pâte rouge, datés du XIII ${ }^{e}$ s. et du début du XIV ${ }^{e}$, produits localement, semblent avoir connu une distribution plus limitée. À côté des fabrications locales, les importations sont peu nombreuses. Pour le XIII ${ }^{e}$ s., on trouve quelques rares exemplaires de Zeuxippus Ware et des vases probablement originaires de Syrie du Nord $\left(\mathrm{n}^{\text {os }}\right.$ 44-45, 60). Il est plus surprenant de constater que les importations continuent au $\mathrm{XIV}^{\mathrm{e}}$ s., avec l'apparition de vases habituellement attribués à une production constantinopolitaine, distribuée essentiellement en mer Noire $\left(n^{\circ} 105\right)$.

La tradition potière de Nicée/Iznik établie maintenant pour les périodes byzantines paraît d'autant plus sûre que la fabrication de vases à pâte argileuse, au décor incisé, champlevé ou peint à l'engobe sous glaçure plombifere s'est maintenue après la conquête ottomane. En effet, ces techniques byzantines ne semblent pas connues des Ottomans antérieurement à la conquête de la Bithynie par Orhan en 1331. C'est seulement après cet événement que les Ottomans ont le savoir-faire nécessaire à la production de vases de tradition byzantine, aussi, il semble très probable qu'il n'y ait pas eu de rupture radicale de la production nicéenne à la suite de la conquête, les potiers ottomans semblant avoir hérité du savoir-faire de leurs prédécesseurs byzantins. La tradition technique byzantine s'est maintenue à Iznik au moins jusqu'au XVI ${ }^{e} s$. Cohabitaient dans la ville deux types d'ateliers : dans les premiers, on fabriquait des faïences peintes monochromes et polychromes, vases de luxe destinés à la cour ; dans les seconds, on réalisait une vaisselle argileuse à glaçure plombifere de tradition byzantine qui répondait à une demande locale mais qui, probablement, était aussi commercialisée plus largement ${ }^{70}$. Tous ces facteurs conduisent désormais à considérer Nicée/Iznik comme un grand centre de production de céramique en activité sur une très longue durée.

Véronique François

69 Distribution régionale attestée par les découvertes faites en prospection dans une grande partie de la Bithynie; pour le détail de cette distribution, voir V. FRANçoIs, loc. cit. (supra, n. 16). 70 V. FrançoIs, loc. cit. (supra, n. 17). 


\section{Catalogue}

\section{Glazed White Ware}

1 (P75) fig. 1.

Forme: $0^{1} /$ fond.

Pâte: argileuse, blanche.

Surface intérieure: rosette à quatre pétales estampée au fond ; glaçure mouchetée, verte.

Surface extérieure: glaçure mouchetée, verte, jusqu'en bas de la panse ; glaçure jaune sur la paroi interne de la base annulaire. $\mathrm{DSP}^{2}=46 ; \mathrm{DIP}=62 ; \mathrm{HEP}=20$; $H I P=14 ; E P F=9$.

2 (P23) fig. 1-2.

Forme: $0 /$ fond.

Pâte: argileuse, blanche.

Surf, int. : sur une couche d'engobe rose, trèfle à quatre feuilles estampé ; glaçure jaune pâle.

$\mathrm{DSP}=65 ; \mathrm{DIP}=70 ; \mathrm{HEP}=11$;

$H I P=3 ; E P F=9$.

3 (P76) fig. 1.

Forme: $0 /$ fond et bas de la panse avec départ d'anses.

Pâte: argileuse, blanche.

Surf. int. : un médaillon central composé de deux cercles concentriques estampés est orné au centre d'un motif indéterminé ; glaçure vert pré, mouchetée.

Surf. ext. : glaçure jusqu'en bas de la base. Sous la base, glaçure jaune. $\mathrm{DSP}=84 ; \mathrm{DIP}=88 ; \mathrm{HEP}=9$; $H I P=5 ; E P F=8$.

\section{4.}

Ltrouv. : Karacakaya.

Forme: $0 /$ fond.

Pâte: argileuse, blanche, grossière. Surf. int. : au fond, une palmette estampée ; glaçure jaune clair appliquée directement sur la pâte.
5 (I 59)

Ltrouv. : Hisarcik.

Forme: $0 /$ frg. de panse.

Pâte: argileuse, blanche.

Surf. int. : motif géométrique

estampé ; glaçure vert bouteille

appliquée directement sur la pâte.

6 (P74) fig. 1.

Forme : $0 /$ fond.

Pâte: argileuse, blanche.

Surf. int. : glaçure jaune pâle brillante.

Aucun motif n'est visible.

$\mathrm{DSP}=70 ; \mathrm{DIP}=72 ; \mathrm{HEP}=13$;

$H I P=6 ; E P F=8$.

7 (IZ.95.40) fig. 1.

Forme: $0 /$ fond et bas de la panse avec départ d'anses.

Pâte: argileuse, blanche un peu rosée avec de petites impuretés rouges.

Surf. int. : glaçure jaune clair, par endroits vert pâle, appliquée directement sur la pâte. Fond irrégulier.

Surf. ext. : glaçure appliquée sans soin jusqu'en bas de la panse.

$\mathrm{DSP}=56 ; \mathrm{DIP}=64 ; \mathrm{HEP}=13$;

$H I P=4 ; E P F=10$.

8 (IZ.95.41).

Forme: $0 /$ fond fragmentaire.

Pâte: argileuse, blanche avec petites impuretés rouges.

Surf. int. : glaçure jaune pâle appliquée directement sur la pâte. $\mathrm{DSP}=57 ; \mathrm{DIP}=64 ; \mathrm{HEP}=14$.

9 (IZ.95.42) fig. 1.

Forme: $0 /$ fond.

Pâte: argileuse, blanche avec petites impuretés rouges.

Surf. int. : glaçure jaune pâle appliquée directement sur la påte. Surf. ext.: engobe rosé appliqué au pinceau (traces visibles) et glaçure jusqu'en bas de la panse. Coulure de glaçure sous la base.
$D S P=55 ;$ DIP $=80 ;$ HEP $=15 ;$

$H I P=15 ; E P F=3$.

10 (IZ.95.44) fig. 1-2.

Forme: $0 /$ fond avec panse

godronnée.

Pâte: argileuse, blanche, fine.

Surf. int.: glaçure en coulures vertes, jaunes et manganèses, très brillante, tressaillée.

Surf. ext. : glaçure jaune pâle et verte jusqu'en bas de la panse.

$\mathrm{DSP}=78 ; \mathrm{DIP}=76 ; \mathrm{HEP}=5$.

11 (IZ.95.45) fig. 1-2.

Forme: $0 /$ bord à marli et haut de panse.

Pâte: argileuse, blanche, fine.

Surf. int.: glaçure en dégradé de jaune brun et vert clair appliquée directement sur la pâte, très brillante. Sur le bord, deux rangées d'incisions parallèles.

Surf. ext. : glaçure jaune jusque sur le haut de la panse.

DSUP $=280 ; \mathrm{DNL}=254 ; \mathrm{HT}=26$;

$\mathrm{HNL}=20$.

12 (P25) fig. 1-2.

Forme: $0 /$ fond.

Pâte: argileuse, blanche.

Surf. int. : motif peint au manganèse sur glaçure jaune pâle. Ensemble très mal conservé.

Surf. ext. : glaçure vert pré jusqu'en bas de la panse.

$\mathrm{DSP}=50 ; \mathrm{DIP}=60 ; \mathrm{HEP}=13$;

$H I P=8 ; E P F=6$.

13 (P24) fig. 1-2.

Forme: $0 /$ fond et bas de la panse.

Pâte: argileuse, blanche.

Surf. int. : sur une fine couche

d'engobe beige, sorte de fleur peinte au manganese-pourpre ; glaçure vert pâle.

Surf. ext. : engobe beige rosé.

$D S P=43 ; \mathrm{DIP}=60 ; \mathrm{HEP}=22$;

$H I P=14 ; E P F=11$.
10 (ouverte); $F$ (fermée) ; PC (profil complet); frg. (fragment). 2 Toutes les dimensions sont données en millimètres. DSUP: diamètre supérieur; ONL: diamètre à la naissance de la lèvre : DPI : diamètre au point d'inflexion; HTC : hauteur totale conservee ; HNL: hauteur à la naissance de la lèvre ; HPI: hauteur au point d'inflexion; EP : épaisseur ; DSP : diamètre supérieur du pied; DIP : diamètre inférieur du pied; HEP: hauteur extérieure du pied ; HIP : hauteur intérieure du pied ; EPF : épaisseur du fond ; Ltrouv. : lieu de trouvaille. 
14 (P26) fig. 1.

Forme: $0 /$ fond plat. Traces de tournage très visibles à l'extérieur et à l'intérieur.

Pâte: argileuse, blanche.

Surf. int. : très endommagée. Petites lignes brunes ; glaçure orangée.

Surf. ext. : glaçure jaune jusqu'en bas de la panse.

$\mathrm{DIP}=40$.

15 (IZ.95.43) fig. 1-2.

Forme: $0 /$ fond et bas de la panse.

Pâte: argileuse, blanche, fine.

Surf. int. : sur glaçure jaune pâle presque incolore - appliquée directement sur la pâte, motif peint au manganèse et en vert sous la forme de coulures.

$\mathrm{DSP}=61 ; \mathrm{DIP}=72 ; \mathrm{HEP}=15$;

$H I P=8 ; E P F=7$.

\section{White Ware rejetée après la $1^{\text {re }}$ cuisson}

16 (IZ.95.38) fig. 1-2.

Forme: $0 /$ fond.

Pâte: argileuse, blanche, fine et rêche au toucher.

DSP $=37 ;$ DIP $=38 ;$ HEP $=10$;

$H I P=6 ; E P F=6$.

17 (IZ.95.39) fig. 1-2.

Forme: $0 /$ fond.

Pâte: argileuse, blanche, fine et rêche au toucher.

$\mathrm{DSP}=87 ; \mathrm{DIP}=72 ; \mathrm{HEP}=22 ;$

$H I P=8 ; E P F=18$

\section{Incised Ware}

\section{Fonds}

18 (4299) fig. 1, 4.

Forme: $0 /$ fond et bas de la panse.

Pâte: argileuse, orange, fine.

Surf. int. : engobe rose ; au fond, un médaillon central constitué d'un bandeau où alternent carreaux champlevés et carreaux en relief ; au centre, un oiseau de profil orienté vers la gauche; du médaillon partent quatre pétales ornés d'un fleuron stylisé. Glaçure orange, brillante. Trace de pernette: un pied arraché. Surf. ext. : sur la panse, bandes en relief appliquées. Engobe et glaçure jusqu'en bas de la panse.

$\mathrm{DSP}=47 ; \mathrm{DIP}=58 ; \mathrm{HEP}=12$;

$H I P=9 ; E P F=10$.

19 (8181).

Forme: $0 /$ fond d'une base annulaire brisée.

Pâte: argileuse, orange vif, fine et un peu grasse.

Surf. int. : engobe blanc; motif incisé et champlevé, dans un médaillon central - composé de deux cercles concentriques formant un bandeau orné de deux spirales superposées alternant avec un trait vertical champlevé - un oiseau de profil orienté vers la droite. Glaçure orange mal conservée. Traces de pernette : deux pieds arrachés.

Surf. ext. : engobe et glaçure jusqu'en bas du pied.

20 (1720) fig. 1.

Forme: $0 /$ fond.

Pâte: argileuse, orange, fine.

Surf. int. : engobe blanc; dans un médaillon central - composé de deux cercles concentriques formant un bandeau orné de spirales alternant avec un trait vertical champlevé - , un oiseau en marche de profil, orienté vers la gauche. Glaçure orange. Traces de pernette: deux pieds arrachés.

Surf. ext. : engobe et glaçure jusqu'en bas de la panse.

DSP $=61 ;$ DIP $=74 ;$ HEP $=11$;

$H I P=11 ; E P F=9$.

21 (2058) fig. 1.

Forme: $0 /$ fond.

Pâte: argileuse, orange, fine et un peu grasse.

Surf. int. : engobe beige ; dans un médaillon - composé de deux cercles concentriques incisés ornés de spirales tracées avec soin -, un oiseau de profil, orienté vers la droite, avec un filet d'eau s'écoulant du bec. Glaçure à peine colorée en jaune pâle.
Traces de pernette : un pied arraché et une marque.

Surf. ext. : engobe et glaçure sur la panse et glaçure appliquée directement sur la pâte, sur le pied. $\mathrm{DSP}=60 ; \mathrm{DIP}=72 ; \mathrm{HEP}=14$; $H I P=11 ; E P F=12$

22 (P40) fig. 1, 4.

Forme: $0 /$ fond.

Pâte: argileuse, rouge brique, dure et fine.

Surf, int. : engobe blanc ; dans un médaillon - composé de deux cercles concentriques incisés ornés de spirales et de points alternés -, un oiseau de profil, orienté vers la gauche, avec un filet d'eau s'écoulant du bec. Glaçure jaune d'or très brillante. Traces de pernette : deux pieds arrachés.

Surf. ext. : engobe et glaçure presque jusqu'en bas de la panse.

$D S P=68 ;$ DIP $=80 ; \mathrm{HEP}=10$;

$H I P=9 ; E P F=7$.

23 (1818.2) fig. 1, 4.

Forme: $0 /$ fond

Pâte: argileuse, orange, fine, un peu grasse.

Surf. int.: engobe blanc ; dans un médaillon central - composé de deux cercles concentriques incisés ornés de spirales - , un oiseau de profil, orienté vers la droite. Glaçure orange très mal conservée. Traces de pernette: deux pieds arrachés. Surf. ext. : engobe et glaçure jusqu'en bas de la panse, glaçure déborde engobe.

DSP $=73 ;$ DIP $=84 ;$ HEP $=12$;

$H I P=8 ; E P F=9$.

24 (1818) fig. 1.

Forme: $0 /$ fond et bas de la panse. Pâte: argileuse, orange vif, un peu grasse.

Surf. int. : engobe blanc; dans un médaillon central composé de deux cercles concentriques incisés, un oiseau de face aux ailes déployées. Glaçure orange. Traces de pernette: trois pieds arrachés. 
Surf. ext. : engobe et glaçure jusqu'en haut du pied, engobe déborde glaçure. Sous la base, une goutte de glaçure. $\mathrm{DSP}=56 ; \mathrm{DIP}=78 ; \mathrm{HEP}=18$; $H I P=15 ; E P F=8$.

25 (1886) fig. 3.

Forme : $0 /$ fond et panse.

Pate: argileuse, rouge brique, fine. Surf. int. : engobe blanc; dans un médaillon central constitué de deux cercles concentriques incisés, un gros oiseau de face, très grossièrement dessiné. Glaçure orange très brillante. Traces de pernette: deux pieds arrachés.

Surf. ext. : engobe jusqu'en bas de la panse et glaçure verte sur tout le vase.

$\mathrm{DSP}=45 ; \mathrm{DIP}=56 ; \mathrm{HEP}=14$;

$\mathrm{HIP}=9 ; \mathrm{EPF}=10$.

\section{6 (4304) fig. 3.}

Forme: $0 /$ fond et bas de la panse. Pâte: argileuse, orange, fine. Surf. int. : engobe blanc; un grand oiseau aux ailes déployées, dessiné avec soin, occupe tout le vase. Glaçure vert sapin.

Traces de pernette: deux pieds arrachés et un arrachement de glaçure. Surf. ext. : engobe et glaçure presque jusqu'en bas de la panse, puis engobe seul.

$\mathrm{DSP}=64 ; \mathrm{DIP}=68 ; \mathrm{HEP}=11$;

$H I P=7 ; E P F=8$.

\section{7 (1896) fig. 3.}

Forme: $0 /$ fond et bas de la panse très fine.

Pâte: argileuse, orange, fine. Surf. int. : engobe blanc ; large médaillon central composé d'un bandeau orné de spirales incisées entre deux cercles concentriques. Glaçure orange. Traces de pernette: trois pieds arrachés.

Surf. ext. : engobe et glaçure jusqu'à la moitié du pied, glaçure déborde engobe.

$D S P=46 ;$ DIP $=56 ; \mathrm{HEP}=11 ;$

$H I P=10 ; E P F=6$.
28 (P65) fig. 3-4.

Forme: $0 /$ fond d'un vase de petites dimensions.

Pâte: argileuse, orange, fine.

Surf. int. : engobe beige ; médaillon central composé d'un bandeau orné de spirales incisées entre deux cercles concentriques. Glaçure orange.

Surf. ext. : engobe et glaçure en coulures jusqu'en bas du pied. $D S P=37 ; D I P=48 ; H E P=10$; $H I P=4 ; E P F=8$.

\section{9 (P49) fig. 3-4.}

Forme: $0 /$ fond d'un vase de petites dimensions.

Pâte: argileuse, rouge foncé, fine, très dure.

Surf. int.: engobe blanchâtre ; médailion central composé d'un bandeau orné de spirales incisées entre deux cercles concentriques. Glaçure orange. Traces de pernette: trois pieds arrachés.

Surf. ext. : engobe et glaçure jusqu'en bas de la panse, puis glaçure sur la base.

DSP $=47 ;$ DIP $=56 ; \mathrm{HEP}=13$;

$H I P=8 ; E P F=5$.

30 (P22) fig. 3-4.

Forme : $0 /$ fond.

Pâte: argileuse, rose, fine, présence de petits grains de quartz.

Surf. int. : engobe rosé ; deux cercles concentriques forment un médaillon central orné d'une demi-palmette incisée. Glaçure orange. Trace de pernette : un pied arraché.

$D S P=43 ;$ DIP $=56 ;$ HEP $=13$; $H I P=14 ; E P F=8$.

31 (P35) fig. 3.

Forme: $0 /$ fond et bas de la panse. Pâte: argileuse, rouge brique, fine, présence de petits grains de quartz. Surf. int. : engobe blanchâtre ; dans un médaillon central - composé de deux cercles concentriques formant un bandeau orné de spirales et lignes verticales incisées - une demipalmette. Glaçure orange brillante.
Traces de pernette : trois pieds arrachés.

Surf. ext. : engobe et glaçure jusqu'à mi-panse, glaçure déborde engobe. $\mathrm{DSP}=34 ; \mathrm{DIP}=52 ; \mathrm{HEP}=13$; $H I P=11 ; E P F=6$.

32 (P36) fig. 3.

Forme: $0 /$ fond.

Pâte: argileuse, orange clair, fine. Surf. int. : engobe blanchâtre ; dans un médaillon central - composé de deux cercles concentriques formant un bandeau orné de spirales -, une demi-palmette. Glaçure jaune d'or. Surf. ext. : glaçure en coulures jusqu'en haut du pied.

$D S P=41 ;$ DIP $=46 ; \mathrm{HEP}=11$; $H I P=8 ; E P F=7$.

33 (P37) fig. 3.

Forme: $0 /$ fond et bas de la panse.

Pâte: argileuse, orange clair, fine, un peu grasse.

Surf. int. : engobe blanc ; deux cercles concentriques forment un petit médaillon central orné d'une palmette incisée. Glaçure jaune d'or. Traces de pernette : trois pieds arraches. $D S P=60 ; D I P=64 ; H E P=10$; $H I P=6 ; E P F=8$.

\section{4 (P16.38) fig. 3-4.}

Forme: $0 /$ fond et bas de la panse. Pâte: argileuse, orange clair, fine avec quelques petits grains de mica.

Surf. int. : engobe blanc; au fond, une double fleur incisée avec au centre une double croix incisée. Glaçure jaune d'or.

Surf. ext. : engobe et glaçure jusqu'au bas de la panse; engobe en coulures sur la base.

$D S P=26 ;$ DIP $=44 ; \mathrm{HEP}=11$;

$H I P=7 ; E P F=8$.

\section{5 (P21.37) fig. 3-4.}

Forme: $0 /$ fond et bas de la panse. Pâte: argileuse, rose, fine avec quelques petits grains de quartz. Surf. int. : engobe rose ; au fond, une double croix incisée. Glaçure jaune d'or. Traces de pernette : un pied 
arraché et deux arrachements de la glaçure.

$\mathrm{DSP}=61 ; \mathrm{DIP}=66 ; \mathrm{HEP}=9$;

$H I P=6 ; E P F=7$.

36 (P38) fig. 3.

Forme: $0 /$ fond.

Pâte: argileuse, orange, fine.

Surf. int. : engobe blanchâtre ; au fond, dans un médaillon central, deux traits rectilignes terminés par une boucle. Glaçure orange. Trace de pernette : un pied arraché.

$\mathrm{DSP}=60 ; \mathrm{DIP}=68 ; \mathrm{HEP}=15 ;$

$H I P=13 ; E P F=8$.

37 (P67).

Forme: $0 /$ fond.

Pâte: argileuse, orange, fine.

Surf. int. : engobe rosé ; double étoile incisée au fond.

Glaçure orange.

Surf. ext.: coulure d'engobe et trace de glaçure.

$\mathrm{DSP}=32 ; \mathrm{DIP}=44 ; \mathrm{HEP}=8$;

$H I P=4 ; E P F=6$.

38 (P41) fig. 3-4.

Forme: $0 /$ fond.

Pâte: argileuse, orange clair, très fine. Surf. int. : engobe blanc ; au fond, deux cercles concentriques champlevés et au centre un petit cercle. Glaçure orange. Traces de pernette : trois pieds arrachés.

Surf. ext. : glaçure sur l'anneau de la base.

$\mathrm{DSP}=66 ; \mathrm{DIP}=68 ; \mathrm{HEP}=10$;

$H I P=6 ; E P F=9$.

39 (P47) fig. 3.

Forme: $0 /$ fond et bas de la panse.

Pâte: argileuse, orange clair, fine.

Surf. int. : engobe blanchâtre ;

succession de six cercles

concentriques incisés depuis le bas

de la panse jusqu'au fond. Glaçure

orange. Traces de pernette : deux

pieds arrachés.

Surf. ext. : engobe et glaçure en coulures irrégulières jusqu'en bas de la panse.

$\mathrm{DSP}=35 ; \mathrm{DIP}=46 ; \mathrm{HEP}=12$;

$H I P=7 ; E P F=6$.
40 (P59) fig. 3-4.

Forme: $0 /$ fond.

Pâte: argileuse, rouge brique, fine.

Surf. int. : engobe blanchâtre ; deux cercles concentriques incisés à la limite entre le bas de la panse et le fond et deux petits cercles au centre. Glaçure orange. Traces de pernette : trois pieds arrachés.

Surf. ext. : engobe et glaçure en coulures irrégulières jusqu'au pied. $\mathrm{DSP}=61 ; \mathrm{DIP}=74 ; \mathrm{HEP}=11$; $H I P=7 ; E P F=7$.

41 (P58) fig. 3.

Forme: $0 /$ fond et bas de la panse.

Pâte: argileuse, grise, trop cuite.

Surf. int. : engobe blanchâtre en très fine couche; deux cercles concentriques incisés à la limite entre le bas de la panse et le fond, au centre une spirale. Glaçure orange. Traces de pernette : deux pieds arrachés.

Surf. ext. : engobe et glaçure en coulures irrégulières jusqu'à mi-panse, puis glaçure seule sur le pied. $\mathrm{DSP}=61 ; \mathrm{DIP}=70 ; \mathrm{HEP}=14$; $\mathrm{HIP}=8 ; \mathrm{EPF}=13$.

42 (IZ.95.25) fig. 3.

Forme: $0 /$ fond et panse.

Pâte: argileuse, orange vif, fine.

Surf. int. : engobe beige ; au fond, une boucle incisée puis à la limite entre le fond et le bas de la panse, deux cercles concentriques incisés. Glaçure vert pré. Traces de pernette : deux pieds arrachés et un arrachement de la glaçure.

Surf. ext. : engobe et glaçure jusqu'à mi-panse ; sous la base une coulure de glaçure.

$\mathrm{DSP}=48 ; \mathrm{DIP}=58 ; \mathrm{HEP}=10$;

$H I P=5 ; E P F=10$.

43 (IZ.95.27).

Forme: $0 /$ fond et bas de la panse. Pâte: argileuse, orange clair, fine. Surf. int. : engobe blanc; entre deux cercles concentriques incisés sur le bas de la panse et au fond, une ligne ondulée. Glaçure orange.
Surf. ext. : engobe en coulures jusqu'en bas du pied.

$\mathrm{DSP}=58 ; \mathrm{DIP}=66 ; \mathrm{HEP}=14$; $H I P=9 ; E P F=4$.

44 (P56) fig. 6.

Forme: 0 /fond.

Pâte: argileuse, orange avec grosses inclusions de quartz.

Surf. int. : engobe blanc; motifs floraux et géométriques incisés rehaussés de pigments verts et brunjaune. Glaçure vert clair. Trace de pernette : un arrachement de glaçure et d'engobe.

Surf. ext. : engobe en coulures. $\mathrm{DSP}=87 ; \mathrm{DIP}=90 ; \mathrm{HEP}=12$.

45 (1724) fig. 6.

Forme: $0 /$ fond et bas de la panse. Pâte: argileuse, orange clair, fine. Surf. int. : engobe blanc ; deux longs poissons représentés tête-bêche incisés avec soin. Glaçure jaune pâle avec rehauts colorés verts et jaunebrun en relation avec le motif. Traces de pernette : deux arrachements de glaçure et d'engobe.

$\mathrm{DSP}=60 ; \mathrm{DIP}=62 ; \mathrm{HEP}=10$; $H I P=8 ; E P F=11$.

\section{Bords}

46 (IZ.95.1) fig. 5.

Forme: $0 /$ bord et haut de la panse. Pâte: argileuse, orange, très fine.

Surf. int. : engobe ; sur le bord, trois cercles concentriques incisés puis deux à mi-panse. Glaçure jaune pâle avec une coulure de pigments verts depuis le bord.

Surf. ext. : engobe et glaçure sur le haut du bord. puis engobe sur le reste du tesson.

DSUP $=180 ; \mathrm{DPI}=170 ; \mathrm{HTC}=40$; $H P I=5 ; E P=4$.

47 (IZ.95.2) fig. 5.

Forme: $0 /$ bord et haut de la panse.

Pâte: argileuse, orange, très fine.

Surf. int. : engobe; trois cercles concentriques incisés sur le haut de la panse. Glaçure orange en partie conservée. 
Surf. ext. : engobe et glaçure sur tout le fragment.

$\mathrm{DSUP}=130 ; \mathrm{HTC}=40 ; \mathrm{EP}=2$.

48 (IZ.95.3) fig. 5.

Forme: $0 /$ bord et haut de la panse.

Pâte: argileuse, orange, très fine.

Surf. int. : engobe ; sur le bord, deux cercles concentriques incisés et un plus fin sur le haut de la panse. Glaçure jaune pâle et verte sur le sommet du bord.

Surf. ext.: engobe et glaçure verte sur le bord, engobe sur toute la panse. DSUP $=120 ; \mathrm{DPI}=140 ; \mathrm{HTC}=26$; $\mathrm{HOI}=9 ; E P=3$.

49 (IZ.95.4) fig. 5. Forme: $0 /$ bord et haut de la panse. Pâte: argileuse, brune, très fine. Surf. int. : engobe ; cinq cercles concentriques incisés du bord au haut de la panse. Glaçure vert clair très brillante.

Surf. ext. : engobe et glaçure sur tout le fragment.

DSUP $=160 ; H T C=40 ; E P=3$.

50 (IZ.95.5) fig. 5.

Forme: $0 /$ bord et haut de la panse.

Pâte: argileuse, brune, très fine.

Surf. int. : engobe blanc; deux cercles concentriques incisés sur le bord.

Glaçure vert sapin.

Surf. ext. : engobe et glaçure sur tout le fragment.

DSUP $=120 ; H T C=23 ; E P=3$.

51 (IZ.95.10) fig. 5.

Forme: $0 /$ bord et haut de la panse.

Pâte: argileuse, orange, très fine.

Surf. int. : engobe ; deux cercles

concentriques incisés sur le haut du

bord et deux autres sur le haut de la

panse. Glaçure jaune pâle. Ensemble mal conservé.

Surf. ext. : engobe et glaçure sur tout le fragment.

$D S U P=190 ; H T C=31 ; E P=4$.

52 (IZ.95.6) fig. 5, 7.

Forme: $0 /$ bord et haut de la panse. Pâte: argileuse, brune, très fine.
Surf. int. : engobe ; quatre cercles concentriques incisés sur le bord puis une ligne ondulée et un autre cercle. Glaçure jaune clair brillante.

Surf. ext. : engobe et glaçure sur le haut du bord, puis engobe seul. DSUP $=120 ; H T C=27 ; E P=3$.

53 (IZ.95.7) fig. 5, 7.

Forme: $0 /$ bord et haut de la panse. Pâte: argileuse, orange, très fine. Surf. int. : engobe blanc; deux cercles concentriques incisés sur le bord et deux autres sur le haut de la panse. Glaçure orange brillante.

Surf. ext. : engobe et glaçure jusqu'à mi-panse, puis engobe.

$\mathrm{DSUP}=150 ; \mathrm{HTC}=26 ; \mathrm{EP}=4$.

54 (IZ.95.9).

Forme: $0 /$ bord et haut de la panse. Pâte: argileuse, orange, très fine.

Surf. int. : engobe blanc; sur le haut de la panse, deux cercles concentriques incisés. Glaçure jaune pâle, très brillante.

Surf. ext. : glaçure sur le bord. DSUP $=150 ;$ HTC $=30$.

55 (IZ.95.8) fig. 5, 7. Forme: $0 /$ bord à marli et haut de la panse.

Pâte: argileuse, orange, très fine. Surf. int. : engobe blanc; deux fois deux cercies concentriques incisés encadrent une ligne ondulée, après le point d'inflexion deux cercles concentriques. Glaçure orange avec une longue coulure de pigments vert sapin.

Surf. ext. : engobe et glaçure kaki sur tout le fragment.

DSUP $=280 ; \mathrm{DPI}=230 ; \mathrm{HTC}=22$; $\mathrm{HPI}=10$.

\section{6 (IZ.95.17) fig. 5.}

Forme: $0 /$ bord et haut de la panse.

Pâte: argileuse, orange, fine.

Surf. int. : engobe ; trois cercles concentriques incisés sur le bord et un sur le haut de la panse. Glaçure orange, brillante et tressaillée. La panse, enfoncée régulièrement au pouce, est ondulee.
Surf. ext. : engobe et glaçure sur tout le fragment.

DSUP $=180 ; \mathrm{HTC}=36$.

57 (IZ.95.18) fig. 5.

Forme: $0 /$ bord et panse.

Pâte: argileuse, orange vif, fine.

Surf. int.: engobe ; trois cercles concentriques incisés sur le bord. Glaçure jaune clair brillante. La panse, enfoncée régulièrement au pouce, a un aspect godronné.

Surf. ext. : engobe et glaçure sur tout le fragment.

DSUP $=220 ; H T=37$.

58 (P30) fig. 5.

Forme: $0 /$ bord et haut de panse. Pâte: argileuse, orange, fine.

Surf. int. : engobe blanchâtre ; sur le bord, trois cercles concentriques incisés puis sur la panse, spirales incisées avec soin. Glaçure jaune très brillante avec rehauts de pigments verts en coulures sur le bord.

Surf. ext. : trois cercles concentriques incisés sur le bord. Engobe et glaçure verte jusqu'à mi-panse. DSUP $=10 ; \mathrm{HTC}=31$.

59 (IZ.95.71).

Forme: $0 /$ frg. de panse.

Pâte: argileuse, brune, fine.

Surf. int. : engobe blanchâtre ; dans

un cadre rectangulaire incisé

profondément, sorte de virgules et de spirales incisées. Glaçure jaune clair.

60 (IZ.95.24) fig. 10.

Forme: $0 /$ bord à marli et haut de la panse.

Pâte: argileuse, orange vif, fine, bien cuite.

Surf. int. : engobe blanchâtre ; sur le marli, bandeau de pétales entre deux fois deux cercles concentriques incisés ; après le point d'inflexion, deux cercles concentriques incisés et un losange aux côtés incurvés. Glaçure incolore avec rehauts de pigments verts, jaunes et manganèse. Surf. ext. : engobe ; succession de lignes ondulées et rectilignes peintes 
en noir. Glaçure incolore très mal conservée. Traces de feu.

\section{Profils complets}

61 (P17.41) fig. 3, 4

Forme: $0 / P C$.

Pâte: argileuse, orange clair, fine et très durc. Parois très fines.

Surf, int. : engobe beige ; au fond, une double fleur incisée avec au centre une double croix incisée. Glaçure orange brillante. Traces de pernette: deux pieds arrachés.

Surf, ext.: sur le bord, rinceau de spirales incisées à l'intérieur d'un bandeau délimité par un et deux cercles concentriques. Engobe et glaçure qui débordent alternativement jusqu'en bas de la panse.

DSUP $=76 ; H T=51 ; \mathrm{DSP}=35$;

$\mathrm{DIP}=44 ; \mathrm{HEP}=9 ; \mathrm{HIP}=7 ; \mathrm{EPF}=6$.

62 (IZK. 94) fig. 3.

Forme: $0 / P C$.

Pâte: argileuse, orange, fine.

Surf. int. : engobe blanchâtre; sur le haut du bord, trois cercles concentriques incisés, au fond une spirale. Glaçure vert pâle avec une coulure de pigments verts sur la spirale et sur le bord.

Trace de pernette: un arrachement de glaçure.

Surf. ext. : engobe et glaçure vert pré appliquée de façon irrégulière jusqu'en bas de la panse avec une coulure de pigments vert bouteille. Glaçure sous le pied.

$\mathrm{DSIP}=95 ; \mathrm{HT}=56 ; \mathrm{DSP}=34$;

$\mathrm{DIP}=45 ; \mathrm{HEP}=13 ; \mathrm{HIP}=19$;

$\mathrm{EPF}=4$.

\section{Ratés de cuisson et vases rejetés en cours d'élaboration}

63 (P37 bis) fig. 2.

Forme: $0 /$ fond.

Pâte: argileuse, orange, assez fine.

Surf. int. : dans un médaillon central composé de deux cercles concentriques incisés, une demipalmette incisée. Aucune trace d'engobe ni de glaçure.
64 (IZ.95.36).

Forme: 0 /fond d'un vase rejeté après la première cuisson.

Pâte: argileuse, orange vif, fine.

Surf. int. : au fond, deux cercles concentriques incisés forment un médaillon central orné d'une fleur incisée directement dans la pâte. Pas de trace d'engobe ni de glaçure.

DIP $=60$.

65 (IZ.95.37) fig. 2.

Forme: $0 /$ fond gondolé, déformé pendant la seconde cuisson.

Pâte: argileuse, grise, trop cuite.

Surf. int. : traces de glaçure jaune craquelée et terne sur engobe blanc. DIP $=52$.

66 (IZ.95.19) fig. 2, 5.

Forme: 0/bord et haut de la panse.

Pâte: argileuse, fine, orange clair à

l'intérieur et grise à l'extérieur.

Surcuit.

Surf. int. : engobe ; trois cercles concentriques incisés sur le bord, puis une ligne ondulée et trois cercles sur la panse. Aucune trace de glaçure. DSUP $=220 ; H T=31$.

67 (IZ.95.20) fig. 5.

Forme: $0 /$ bord et haut de la panse. Pâte: argileuse, orange clair, fine.

Surf. int. : engobe beige ; trois cercles concentriques incisés sur le bord, puis sorte de chevrons sur la panse.

Aucune trace de glaçure.

Surf. ext. : engobe sur tout le fragment.

DSUP $=210 ; \mathrm{DPI}=203 ; \mathrm{HTC}=42$; $\mathrm{HPI}=25$.

68 (P43) fig. 6.

Catégorie: Zeuxippus Ware, classe IA. Forme: $0 /$ fond.

Pâte: argileuse, rouge brique, très fine.

Surf. int. : engobe blanchâtre ; en bas de la panse, large bandeau champlevé, puis un et deux cercles concentriques incisés. Glaçure jaune pâle très brillante.

Surf. ext. : glaçure jusqu'en bas de la panse appliquée directement sur la pâte, une goutte sous l'anneau de la base.

$\mathrm{DSP}=29 ; \mathrm{DIP}=40 ; \mathrm{HEP}=12$;

$H I P=13 ; E P F=6$.

69 (P28) fig. 6-7.

Catégorie: Zeuxippus Ware, classe IB. Forme: $0 /$ fond et panse.

Pâte: argileuse, rouge brique, très dure, très cuite, fine malgré quelques petites inclusions de quartz.

Surf. int. : engobe blanchâtre ; au fond, un médaillon central excisé entouré par un cercle concentrique incisé, à mipanse, un bandeau excisé, délimité par deux cercles concentriques, rempli de points peints à l'engobe. Glaçure orange très brillante. Traces de pernette: deux pieds arrachés et un arrachement de glaçure.

Surf. ext. : à mi-panse, deux cercles concentriques peints à l'engobe, puis deux rinceaux de spirales superposés agrémentés de points peints à l'engobe. Glaçure orange, aspect marron sur la pâte, jusqu'au milieu de la panse.

$\mathrm{DSP}=42 ; \mathrm{DIP}=88 ; \mathrm{HEP}=24$;

$H I P=31 ; E P F=9$.

70 (P29) fig. 6.

Catégorie: Zeuxippus Ware, classe IB. Forme: $0 /$ fond et bas de la panse. Pâte: argileuse, orange, fine, très cuite.

Surf. int. : engobe blanchâtre ; médaillon central composé de deux bandeaux excisés dont l'un est orné de points peints à l'engobe, le tout entouré par un cercle concentrique incisé. Glaçure jaune clair très mal conservée.

Surf. ext. : spirales peintes à l'engobe sur la panse. Glaçure jaune clair, quelques coulures jusqu'au bas de la panse.

$\mathrm{DSP}=39 ; \mathrm{DIP}=52 ; \mathrm{HEP}=13$;

$H I P=11 ; E P F=8$.

$71(4300 / 23)$ fig. 6-7.

Catégorie: Zeuxippus Ware, classe II. Forme: $0 /$ fond.

Pâte: argileuse, orange, fine, bien cuite. 
Surf. int. : engobe blanc ; représentation figurée non identifiée. incisée, rehaussée çà et là de pigments bruns. Glaçure jaune pâle, brillante. Trace de pernette : un pied de forme triangulaire arraché.

Surf. ext.: engobe et glaçure presque jusqu'en bas de la panse, glaçure déborde engobe jusqu'en bas du pied. $D S P=43 ;$ DIP $=52 ; \mathrm{HEP}=9$; $H I P=14 ; E P F=5$.

72 (4305/22) fig. 6-7. Catégorie: Zeuxippus Ware, classe II. Forme: $0 /$ fond.

Pâte: argileuse, rouge, fine, bien cuite.

Surf. int.: engobe blanc : représentation figurée non identifiée, incisée, rehaussée de pigments bruns. Glaçure jaune pâle, brillante. Trace de pernette : un pied arraché. Surf. ext. : engobe et glaçure jusqu'en bas de la panse.

DSP $=79 ;$ DIP $=88 ;$ HEP $=9$; $H I P=11 ; E P F=7$.

73 (IZ.95.31).

Catégorie: Zeuxippus Ware, classe II. Forme: $0 /$ fond.

Pâte: argileuse, orangée, fine, bien cuite.

Surf. int. : engobe blanc ; motif incisé rehaussé de pigments jaune d'or. Glaçure incolore, brillante.

Surf. ext.: engobe et glaçure en coulures jusque sous la base. $\mathrm{DSP}=87 ; \mathrm{DIP}=90 ; \mathrm{HEP}=7$.

\section{Slip Painted Ware}

\section{Fonds}

74 (P4) fig. 8.

Forme: $0 /$ fond et bas de la panse.

Pâte: argileuse, orange, fine.

Surf. int. : au fond, deux cercles concentriques peints à l'engobe ornés de points. Glaçure jaune d'or, effet orange sur la pâte. Traces de pernette : un pied arraché et un arrachement de la glaçure.
Surf. ext. : glaçure appliquée directement sur la pâte jusqu'en haut du pied.

DSP $=74 ;$ DIP $=84 ;$ HEP $=14$;

$H I P=5 ; E P F=6$.

75 (IZ.95.33) fig. 7-8.

Forme: $0 /$ fond et bas de la panse.

$P a$ ate: argileuse, orange vif, fine.

Surf. int. : au fond, un cercle peint à

l'engobe rempli de points est souligné par un cercle constitué de points.

Glaçure orange, effet marron sur la

pâte. Traces de pernette: deux pieds arrachés.

Surf. ext. : glaçure appliquée directement sur la pâte jusqu'en haut du pied.

$\mathrm{DSP}=62 ; \mathrm{DIP}=70 ; \mathrm{HEP}=12$;

$H I P=9 ; E P F=6$.

76 (IZ.95.32).

Forme: $0 /$ fond et bas de la panse.

Pâte: argileuse, ocre, fine.

Surf. int. : au fond, un cercle peint à l'engobe souligné par un cercle constitué de points. Glaçure orange, effet marron sur la pâte.

Surf. ext. : glaçure appliquée directement sur la pâte jusqu'en bas du pied.

\section{7 (P3) fig. 8.}

Forme: $0 /$ fond et bas de la panse.

Pâte: argileuse, rouge brique, fine, un peu grasse.

Surf. int. : semis de points peints a

l'engobe. Glaçure orange, effet marron sur la pâte. Traces de pernette : trois pieds arrachés. Surf. ext. : grands cercles peints à l'engobe sur la panse et glaçure jusqu'en bas du pied.

$\mathrm{DSP}=73 ; \mathrm{DIP}=80 ; \mathrm{HEP}=10$;

$H I P=6 ; E P F=13$.

78 (P31) fig. 7-8.

Forme: $0 /$ fond et bas de la panse. Pâte: argileuse, orange, fine.

Surf. int. : damier peint à l'engobe dont chaque case contient un petit cercle. Glaçure vert pistache brillante, effet brun sur la pâte.
Traces de pernette: deux pieds arrachés.

Surf. ext. : cercles peints à l'engobe sur la panse ; glaçure appliquée en coulures directement sur la pâte jusqu'en bas du pied.

$\mathrm{DSP}=41 ; \mathrm{DIP}=52 ; \mathrm{HEP}=13$;

$H I P=11 ; E P F=5$.

79 (P5) fig. 7-8.

Forme: $0 /$ fond et bas de la panse. Pâte: argileuse, rouge brique, fine. Surf. int. : damier peint à l'engobe dont chaque case contient un petit cercle. Glaçure jaune d'or, effet orange sur la pâte. Traces de pernette : trois pieds arrachés. Surf. ext. : cercles peints à l'engobe sur la panse ; glaçure appliquée directement sur la pâte jusqu'en bas du pied.

$\mathrm{DSP}=50 ; \mathrm{DIP}=58 ; \mathrm{HEP}=10$;

$H I P=6 ; E P F=8$.

80 (P6) fig. 7-8.

Forme: $0 /$ fond.

Pâte: argileuse, orange, fine, un peu grasse.

Surf. int. : rangs de virgules peintes à l'engobe. Glaçure jaune d'or, effet orange sur la pâte.

Surf. ext. : glaçure appliquée directement sur la pâte jusqu'en bas du pied.

$\mathrm{DSP}=46 ; \mathrm{DIP}=50 ; \mathrm{HEP}=11$;

$H I P=4 ; E P F=8$.

81 (IZ.95.72).

Forme: $0 /$ fond très fragmentaire et bas de la panse.

Pâte: argileuse, orange, fine.

Surf. int. : rinceaux de grandes spirales peintes à l'engobe agencées en mouvement concentrique. Glaçure jaune pâle, effet orange sur la pâte. Surf. ext. : spirales peintes à l'engobe et glaçure jusqu'en bas de la panse.

82 (IZN.87. Ara. Sok.51.4407) fig. 7. Forme: F/fond et panse d'une cruche à une anse.

Pâte: argileuse, orange foncé, fine. Surf. int. : aucun. 
Surf. ext. : lignes verticales ondulées alternent avec des successions de points peints à l'engobe. Glaçure orange, effet marron sur la pâte, jusqu'à mi-panse.

$\mathrm{DIP}=58 ; \mathrm{HTC}=90$.

83 (P72).

Forme: $F /$ fond et panse avec départ du goulot d'une cruche.

Pâte: argileuse, orange vif, assez fine. Surf. ext. : lignes verticales ondulées peintes à l'engobe. Glaçure jaune d'or, effet orange sur la pâte.

$\mathrm{HTC}=85$.

\section{Bords}

84 (P2) fig. 8.

Forme: $0 /$ bord et haut de panse.

Pâte: argileuse, rouge brique, fine.

Surf. int. : sur la panse, cercle peint à l'engobe souligné par un cercle de points. Glaçure jaune pâle, effet marron sur la pâte.

Surf. ext. : glaçure jusqu'au point d'inflexion.

DSUP $=250 ;$ DNL $=252 ; \mathrm{DPI}=256$;

$\mathrm{HT}=60 ; \mathrm{HNL}=56 ; \mathrm{HPI}=30$.

85 (P7) fig. 8.

Forme: $0 /$ bord et haut de panse.

Pâte: argileuse, orange, fine.

Surf. int. : sur la panse, petits cercles peints à l'engobe soulignés par des cercles de points. Glaçure jaune d'or, effet orange sur la pâte.

Surf. ext. : glaçure sur tout le fragment. DSUP $=200 ; \mathrm{HT}=36$.

86 (IZ.95.34) fig. 8.

Forme: $0 /$ bord.

Pâte: argileuse, orange, fine.

Surf. int. : engobe blanchâtre et glaçure jaune pâle tressaillée.

Surf. ext. : virgules alternant avec un point, peintes à l'engobe. Glaçure jaune pâle, effet orange sur la pâte. DSUP $=140 ; H T C=18$.

\section{Profil complet}

87 (IZ.94.3) fig. 8.

Forme: $0 / \mathrm{PC}$

Pâte: argileuse, orange, fine.

Surf. int. : rinceau de grandes spirales peintes à l'engobe agencé en mouvement concentrique autour d'un point central ; sur le bord, succession de points peints à l'engobe. Glaçure jaune pâle, effet orange sur la pâte. Surf. ext. : rinceau de grandes spirales peintes à l'engobe sur la panse. Glaçure jaune pâle qui a presque complètement disparu. DSUP = $124 ;$ DNL = $117 ; \mathrm{DPI}=119$; $\mathrm{HT}=75 ; \mathrm{HNL}=68 ; \mathrm{HPI}=56$; DDSP $=29 ;$ DIP $=54 ; \mathrm{HEP}=17$; $H I P=14 ; E P F=9$.

\section{Plain Glazed Ware}

\section{Fonds}

88 (IZ.95.29) fig. 6.

Forme: $0 /$ fond et bas de la panse d'un vase de très petites dimensions. Pâte: argileuse, orange vif, fine.

Surf. int. : engobe rosé et glaçure kaki brillante.

DSP $=16 ;$ DIP $=34 ;$ HEP $=9$;

$H I P=11 ; E P F=4$.

89 (IZ.95.30) fig. 6.

Forme: $0 /$ fond et bas de la panse d'un vase de très petites dimensions. Pâte : argileuse, orange vif, fine.

Surf. int. : glaçure kaki appliquée directement sur la pâte. Traces de pernette : deux pieds arrachés et un arrachement de glaçure.

$\mathrm{DSP}=18 ; \mathrm{DIP}=32 ; \mathrm{HEP}=9$;

$\mathrm{HIP}=14 ; \mathrm{EPF}=4$

90 (IZ.95.28) fig. 6.

Forme: $F /$ fond et bas de la panse d'un vase de très petites dimensions. Pâte: argileuse, ocre, fine.

Surf. int. : engobe blanchâtre et glaçure incolore, brillante et tressaillée. Surf. ext. : engobe et glaçure incolore rehaussée de coulures de pigments verts.
$\mathrm{DSP}=33 ; \mathrm{DIP}=32 ; \mathrm{HEP}=5 ;$

$H I P=1 ; E P F=5$.

\section{Bords}

91 (IZ.95.16) fig. 6.

Forme : 0/bord.

Pâte: argileuse, orange vif, très fine. Surf. int. : engobe blanchâtre et glaçure vert bouteille très brillante. Surf. ext. : engobe et glaçure sur tout le fragment.

DSUP $=150 ;$ HTC $=23$.

92 (IZ.95.11) fig. 6.

Forme: $0 /$ bord et panse très fine d'un vase de petites dimensions.

Pâte: argileuse, orange clair, fine. Surf. int.: engobe blanc et glaçure jaune pâle brillante.

Surf. ext. : engobe et glaçure jusqu'à mi-panse puis engobe seul. DSUP $=100 ; \mathrm{DPI}=90 ; \mathrm{HTC}=36$; $H P I=28 ; E P=2$.

\section{Profils complets}

93 (IZN.94.2) fig. 6.

Forme: 0/PC.

Pâte: argileuse, orange clair, fine. Surf, int. : engobe rosé appliqué de façon irrégulière et glaçure vert émeraude brillante.

Surf. ext.: engobe et glaçure appliqués de façon irrégulière jusqu'en bas de la panse. DSUP $=108 ; H T=64 ;$ DSP $=36$; $\mathrm{DIP}=46 ; \mathrm{HEP}=13 ; \mathrm{HIP}=13$; $E P F=10$.

94 (P.30 bis) fig. 6.

Forme: 0/PC.

Pâte: argileuse, orange vif, fine. Surf. int. : engobe blanchâtre et glaçure jaune pâle, tressaillée. Traces de pernette: trois arrachements de glaçure.

Surf. ext. : engobe et glaçure jusqu'à mi-panse, puis glaçure seule.

$\mathrm{DSUP}=90 ; \mathrm{DPI}=78 ; \mathrm{HT}=63$;

$\mathrm{HPI}=32 ; \mathrm{DSP}=35 ; \mathrm{DIP}=44$;

$\mathrm{HEP}=17 ; \mathrm{HIP}=14 ; \mathrm{EPF}=7$. 


\section{Champlevé}

95 (P14.53) fig. 10.

Forme: $0 /$ fond.

Pâte: argileuse, rouge sombre, très

dure, très compacte.

Surf. int. : engobe rosé ; aile

champlevée et incisée de "l'oiseau de

Thessalonique ". Glaçure kaki, effet

noir dans les incisions.

Surf. ext. : une coulure de glaçure

sous la base.

$\mathrm{DSP}=59 ; \mathrm{DIP}=68 ; \mathrm{HEP}=10$;

$H I P=10 ; E P F=8$.

\section{6 (P11) fig. 9.}

Forme: $0 /$ fond et bas de la panse. Pâte: argileuse, orange clair, fine.

Surf. int. : engobe blanc; dans un médaillon central, un damier excisé dont les cases en relief sont rehaussées d'une tache de pigments verts; sur la panse, croisillons incisés. Glaçure jaune pâle. Traces de pernette : deux pieds arrachés et un arrachement de glaçure et d'engobe. $\mathrm{DSP}=47 ; \mathrm{DIP}=62 ; \mathrm{HEP}=18$; $H I P=19 ; E P F=10$.

97 (P27) fig. 8, 10.

Forme: 0 /fond.

Pâte: argileuse, orange clair, fine. Surf. int. : engobe beige; au centre, une fleur champlevée à six pétales rehaussée de pigments verts. Glaçure jaune pâle. Trace de pernette: un pied arraché.

$\mathrm{DSP}=47 ; \mathrm{DIP}=64 ; \mathrm{HEP}=23$;

$H I P=27 ; E P F=10$.

98 (P63) fig. 8.

Forme: $0 /$ fond.

Pâte: argileuse, orange, fine.

Surf. int. : engobe blanchâtre ; dans un médaillon central, une fleur champlevée à huit pétales rehaussés de pigments verts. Glaçure jaune pâle. Traces de pernette : deux pieds arrachés.

$\mathrm{DSP}=52 ; \mathrm{DIP}=68 ; \mathrm{HEP}=26$;

$H I P=25 ; E P F=13$.
99 (P9) fig. 8.

Forme : $0 /$ fond.

Pâte: argileuse, orange clair, fine.

Surf. int. : engobe ; motif rayonnant champlevé, dans chaque compartiment triangulaire un losange incisé, divisé en quatre cases ornées d'un point et rehaussées de pigments verts. Glaçure jaune pâle. Trace de pernette : un pied arraché.

$\mathrm{DSP}=45 ; \mathrm{DIP}=58 ; \mathrm{HEP}=17$; $H I P=21 ; E P F=6$.

100 (P10.50) fig. 8, 10.

Forme: $0 /$ fond.

Pâte: argileuse, rouge brique, très fine.

Surf. int. : engobe ; au milieu d'un entrelacs excisé rehaussé de pigments verts, un petit arbre incisé. Glaçure jaune pâle.

Surf. ext. : aucun. Sur le lit de pose de la base annulaire, deux morceaux de pernette arrachée.

$\mathrm{DSP}=41 ; \mathrm{DIP}=67 ; \mathrm{HEP}=17$;

$H I P=19 ; E P F=11$.

101 (P13.47) fig. 8, 10.

Forme: $0 /$ fond très endommagé.

Pâte: argileuse, rose, fine.

Surf. int. : engobe rosé ; dans un médaillon central constitué de trois cercles concentriques incisés, quatre bandes entrelacées rehaussées de pigments verts se détachent d'un fond hachuré et orné de spirales incisées : sur le bas de la panse, une spirale incisée. Glaçure jaune pâle. Traces de pernette : un pied arraché.

$\mathrm{DSP}=41 ; \mathrm{DIP}=60 ; \mathrm{HEP}=23$;

$H I P=25 ; E P F=10$.

102 (4135) fig. 9.

Forme: $0 /$ fond.

Pâte: argileuse, orange, fine.

Surf. int. : engobe blanc; un poisson incisé. Glaçure jaune pâle avec rehauts de pigments verts.

Surf. ext. : coulures d'engobe.

$\mathrm{DSP}=57 ; \mathrm{DIP}=76 ; \mathrm{HEP}=24$;

$H I P=26 ; E P F=7$.
103 (P64) fig. 9.

Forme: $0 /$ fond.

Pâte: argileuse, orange clair, fine.

Surf. int. : engobe blanc; motif zoomorphe indéterminé incisé. Glaçure jaune pâle avec une tache diffuse verte.

$\mathrm{DSP}=51 ; \mathrm{DIP}=66 ; \mathrm{HEP}=19$; $H I P=20 ; E P F=9$.

104 (1867) fig. 9.

Forme: $0 /$ fond très endommagé. Pâte: argileuse, rouge brique, fine. Surf. int. : engobe blanc ; au cœur d'un système d'entrelacs, un visage stylisé champlevé. Glaçure jaune clair très brillante. Traces de pernette: un pied arraché et un arrachement de glaçure.

$\mathrm{DSP}=62 ; \mathrm{DIP}=74 ; \mathrm{HEP}=11$;

$H I P=10 ; E P F=12$.

105 (P22.51) fig. 10.

Forme: $0 /$ bord.

Pâte: argileuse, brune, fine.

Surf. int. : engobe blanchâtre ; sur le bord, spirales très finement incisées puis, sur la panse, succession de feuilles finement nervurées traitées au champlevé. Glaçure jaune très brillante.

Surf. ext. : engobe ; sur le bord, un bandeau hachuré de lignes verticales incisées ; sur la panse, sorte de godrons incisés et champlevés. Glaçure verte.

$E P=4$.

106 (P8.55) fig. 9.

Forme : $0 /$ fond.

Pâte: argileuse, orange clair, fine.

Surf. int. : engobe beige ; motif rayonnant générant des compartiments triangulaires dont un sur deux est orné de spirales incisées. Glaçure jaune pâle avec rehauts de pigments manganèses. Trace de pernette : un pied arraché. Surf. ext. : gouttes dispersées d'engobe et de glaçure. $D S P=66 ;$ DIP $=78 ;$ HEP $=21$; $H I P=16 ; E P F=9$ 


\section{Raté de culsson et vase rejeté en cours d'élaboration}

107 (IZ.95.35) fig. 9-10.

Forme: $0 /$ fond d'un vase rejeté après la deuxième cuisson.

Pâte: argileuse, cœur noir et extérieur brun clair, surcuite.

Surf. int. : engobe ; fragment de l'aile de "l'oiseau de Thessalonique ". Glaçure kaki. L'aile est en partie interrompue par le fond collé d'un autre vase.

$\mathrm{DSP}=45 ; \mathrm{DIP}=64 ; \mathrm{HEP}=20$; $H I P=19 ; E P F=11$

108 (P71).

Forme: $0 /$ fond d'un pied déformé. Pâte: argileuse, noire, surcuite. Surf. int. : engobe ; dans un médaillon central entouré d'une bande ondulée, un damier excisé. Glaçure kaki. Un gros morceau de pernette est resté collé. 